\title{
REVIEW
}

\section{Dimerization and oligomerization of G-protein-coupled receptors: debated structures with established and emerging functions}

\author{
László Szidonya ${ }^{1}$, Miklós Cserzó ${ }^{1}$ and László Hunyady ${ }^{1,2}$ \\ ${ }^{1}$ Department of Physiology, Semmelweis University, PO Box 259, H-1444 Budapest, Hungary \\ ${ }^{2}$ Laboratory for Neurobiochemistry and Molecular Physiology, Hungarian Academy of Sciences and Semmelweis University, H-1444 Budapest, Hungary \\ (Correspondence should be addressed to L Hunyady; Email: hunyady@puskin.sote.hu)
}

\begin{abstract}
Dimerization or oligomerization of G-protein-coupled receptors (GPCRs) is a novel concept, which may lead to the reevaluation of the actions of pharmacological ligands, hormones, neurotransmitters, and other mediators acting on GPCRs. Although a large number of data obtained using different biophysical, biochemical and structural methods, and functional approaches argue for dimerization or oligomerization of these receptors, several publications criticized the applied methods and challenged the concept. The aim of this paper is to review the data that support the concept of receptor oligomerization, and the most important arguments against it. We conclude that it will require major methodical improvements to obtain decisive proof, whether GPCRs exist in their native membrane environments as
\end{abstract}

homo- or heterodimeric or oligomeric complexes, in which receptor monomers have stable direct interactions. However, overwhelming amounts of data suggest that many GPCRs exhibit functional properties that require direct or indirect interactions between clustered receptors. Although it is difficult to conclude, about the exact nature of these interactions, dimerization or oligomerization of GPCRs is a useful paradigm for pharmacologists to study properties of receptors, which require functionally important clustering of receptors, such as trafficking of newly synthesized receptors to the cell surface, allosteric modulation of ligand binding, signaling specificity, co-internalization, or cross-inhibition of GPCRs.

Journal of Endocrinology (2008) 196, 435-453

\section{Introduction}

The superfamily of the G-protein-coupled receptors (GPCRs) makes up the largest group of membrane receptors (Fredriksson \& Schioth 2005). They respond to a large variety of stimuli, including biogenic amines, peptides, glycoproteins, neurotransmitters, odorants, ions, lipids, nucleotides, light, or even protease enzymes, and they transduce these signals across the plasma membrane by coupling to heterotrimeric G-proteins and G-protein-independent signaling pathways (Bockaert \& Pin 1999, Wei et al. 2003, Luttrell 2006). Their importance is indicated by the fact that about half of the drugs used in clinical practice directly or indirectly modify the activity of a GPCR (Tyndall \& Sandilya 2005, Jacoby et al. 2006). The common structural feature of GPCRs is the seven transmembrane (TM) $\alpha$-helical domains, each composed of 25-35 amino acid residues. The highly hydrophobic helices are connected by three extracellular and three intracellular loops, while the $\mathrm{N}$ terminus is extracellular and the $\mathrm{C}$ terminus is intracellular. This typical structure gave rise to an alternative name for these molecules, seven TM or 7-TM receptors, which has the advantage of accommodating the fact that their signal transduction is not limited to G-proteins (Hunyady \& Catt 2006, Luttrell 2006).

Based on sequence homology and structural features, GPCRs are traditionally arranged in four groups: family A (or class I) receptors, which includes rhodopsin, activated by small ligands or short peptides; family B (class II) receptors (e.g. secretin-receptor) have a longer $\mathrm{N}$-terminal domain and bind large peptides; family C (class III) GPCRs are characterized by a very large $\mathrm{N}$ terminus, and bind small ligands such as glutamate or GABA (metabotropic glutamate receptors, $G_{A B A}-R$ ); and for e.g. the frizzled/smoothened family. A more recent classification divides the receptors into the glutamate, rhodopsin, adhesion, frizzled/taste2, and secretin families (Fredriksson et al. 2003). A continually updated list of GPCRs is available at http://www.iupharbb. org/receptorList/results.php (Foord et al. 2005). The natural ligand is presently unknown for many of these receptors hence they are the so-called 'orphan' receptors.

Contrary to a large number of membrane proteins, e.g. tyrosine-kinase receptors, GPCRs were initially considered to 
be monomeric entities, coupling to a single G-protein heterotrimer with a 1:1 stoichiometry. In recent years a lot of data accumulated, which challenged this view, suggesting that some GPCRs can exist as dimers or higher-order oligomers (Bouvier 2001, Kroeger et al. 2003, Milligan et al. 2003, Terrillon \& Bouvier 2004, Milligan \& Bouvier 2005, Milligan 2006, Minneman 2007). Most available methods do not distinguish dimerization or oligomerization of GPCRs, therefore we prefer to refer to this process as GPCR oligomerization. While the functional significance of this process is still not completely understood, and in some cases even the applied methodological approaches are debated (Chabre \& le Maire 2005, James et al. 2006), it is now increasingly accepted that oligomerization of GPCRs can be important for receptor expression and function, including agonist binding, potency, efficacy, and G-protein selectivity. However, whether oligomerization is fundamentally important for all GPCRs is still controversial, which is not surprising, given the large number of receptors belonging to this group and the diverse functions they mediate.

In this paper, our goal is to use examples to present different arguments for and against the concept of receptor dimerization or oligomerization, comparing the advantages and disadvantages of the applied methods, and to integrate some exciting recent data into the picture of this complex and rapidly expanding field.

\section{Indirect indications of GPCR oligomerization}

Soon after the direct identification of $\beta$-adrenergic receptors by radioligand binding in frog erythrocytes (Mukherjee et al. 1975), negative cooperativity was observed among the binding sites, which raised the possibility of physical interactions between individual receptor monomers (Limbird \& Lefkowitz 1976). The functional significance of clustered receptors organized by receptor-receptor interactions was first hypothesized a quarter of a century ago (Agnati et al. 1982). The activating role for receptor aggregation was also postulated, when an antagonist of the gonadotropin-releasing hormone $(\mathrm{GnRH})$ was converted into an agonist after incubation with a bivalent antibody against the antagonist. The latter results suggested that a pure antagonist can act as an agonist when it is capable of bringing two receptor molecules within a critical distance, between 15 and $150 \AA$ ( 1.5 and $15 \mathrm{~nm}$; Conn et al. 1982). Other observations supporting the idea that GPCRs might form oligomeric complexes came from radiation inactivation, photo-affinity labeling, crosslinking, and gel filtration experiments performed in the $1970 \mathrm{~s}$ and 1980s (reviewed in Bouvier (2001)).

Another line of evidence came from trans-complementation studies in which the co-expression of two nonfunctional mutant or chimeric receptors resulted in the restoration of function. In a classical study, two chimeric receptors, one containing the first five TM domains of the $\alpha_{2}$-adrenergic receptor and the last two TMs of the M3 muscarinic acetylcholine receptor (M3-AchR), and the other vice versa, were used (Maggio et al. 1993a). When expressed alone, both of these receptors were nonfunctional, showing no binding of muscarinic or adrenergic antagonists. Co-expression of the two constructs resulted in a partial restoration of binding for both of the receptors, and signaling through the M3AchR. In the same study, a similar restoration of function was observed between two differently mutated M3-AchRs as well, suggesting both hetero- and homo-oligomerization of this receptor. In a similar experiment, two mutants of the type 1 angiotensin II receptor $\left(\mathrm{AT}_{1} \mathrm{R}\right.$ ) were studied (Monnot et al. 1996). Both K102A (in TM3) and K199A (in TM5) point mutant receptors did not bind the peptide agonist or nonpeptide antagonist of the $\mathrm{AT}_{1} \mathrm{R}$ when expressed alone, while co-expression of the two restored the binding site, but not the G-protein activation. These papers led to the idea of the 'domain-swapping' model of dimerization in which two independent folding units of the receptor separate and recombine between the two protomers of the dimer (Fig. 1B). In the 'contact dimerization' or 'lateral packing' model (Fig. 1A), the integrity of the receptor monomers is maintained (Kroeger et al. 2003).

In the case of domain-swapping, the folding units are believed to be made up from the first five and the last two TM domains, connected by the third intracellular loop as a 'hinge', allowing the units to separate (Gouldson et al. 2000). This is supported by the observation that truncated M2- and M3-AchRs, split in their third intracellular loop into N- and C-terminal fragments, which do not bind ligands when expressed alone, can reassemble into functional receptors capable of binding and signaling (Maggio et al. 1993b). Alternatively, the second intracellular loop can also act as a 'hinge', as indicated by studies involving M3-AchR (Schoneberg et al. 1995) and $\mathrm{AT}_{1} \mathrm{R}$ (Monnot et al. 1996).

Other studies did not find evidence of such functional rescue between co-expressed V2 vasopressin (Schulz et al. 2000) or $\mathrm{D}_{2}$ dopamine receptor mutants (Lee et al. 2000), despite demonstrating dimerization of the molecules. These findings support the concept of contact dimerization in which the GPCRs directly contact each other using interaction sites on the exterior of the TM domains. It is quite possible that the two kinds of dimers may co-exist although the contact dimers would be more favorable energetically, as their formation does not require the rearrangement of the TM domains between the receptors. This notion is supported by the observation that after a highly conserved extracellular disulfide bond was mutationally disturbed in the V2 receptor, it was able to form a domainswapped construct with a co-expressed receptor fragment (Schulz et al. 2000). Quite often, the number of binding sites recovered in domain-swapping experiments is much lower than that of the wild-type receptor, which also suggests the energetically unfavorable nature of this kind of interaction (Bakker et al. 2004).

Theoretically, both models of dimerization may be extended to the formation of higher-order oligomeric structures. In the case of contact dimers, a second set of 
A

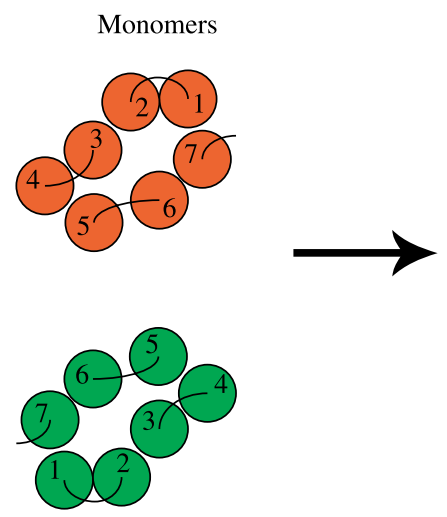

$\mathrm{B}$

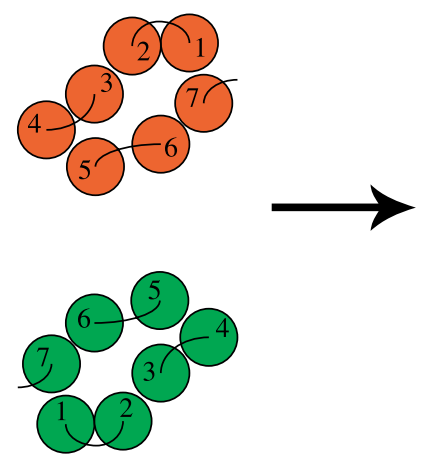

Contact dimer

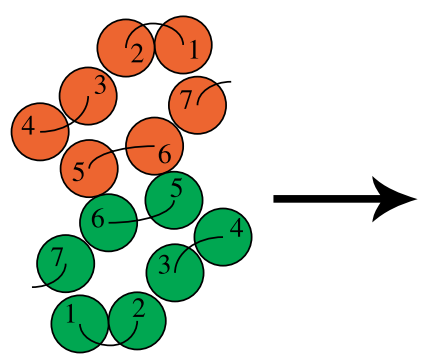

Domain-swapped dimer

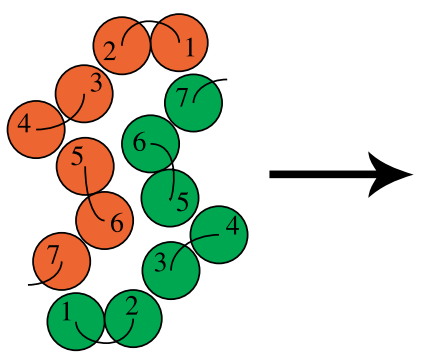

Oligomerization
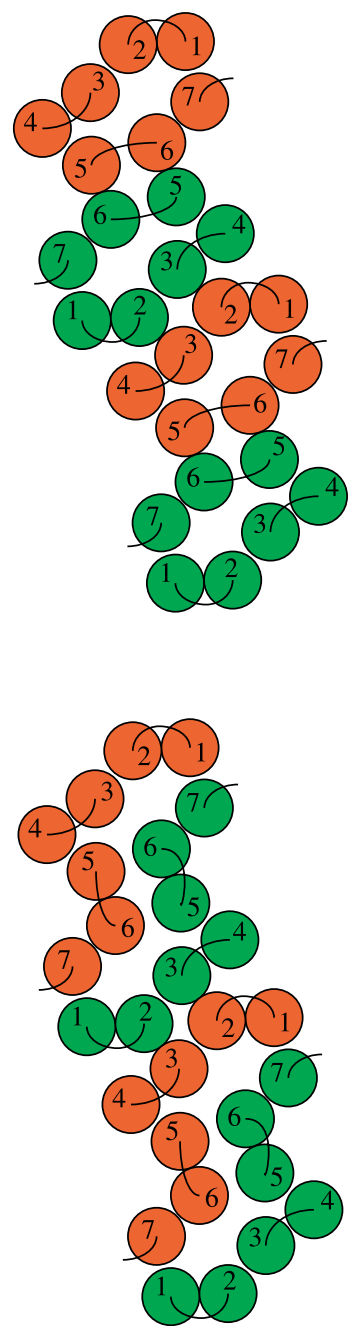

Figure 1 Possible mechanisms of the formation of GPCR dimers and oligomers. (A) In the contact dimer or lateral packing model, GPCRs directly contact each other via exterior residues of the transmembrane domains. These dimers may associate at other interacting surfaces leading to the formation of receptor oligomers. (B) The domain-swapping model requires changes in the integrity of the monomers by swapping of independently folded transmembrane domains between GPCR monomers. Theoretically, lateral packing dimerization of domain-swapped dimers would also make possible the formation of higher-order oligomers.

interaction points would provide the link between the dimers, whereas domain-swapped dimers could form oligomers by lateral packing (Fig. 1).

\section{Biochemical methods to detect GPCR oligomerization}

Co-immunoprecipitation is the most frequently used biochemical approach to detect the oligomerization of GPCRs. This is commonly accomplished using differentially epitope-tagged molecules expressed in recombinant systems. In the first application of this technique to study receptor dimerization, $\beta_{2}$-adrenergic receptors $\left(\beta_{2} \mathrm{AR}\right)$ tagged with influenza hemagglutinin (HA)- and myc-tags were co-expressed in Sf9 cells, and after immunoprecipitation with an anti-myc antibody, the dimer could be detected using an antiHA antibody (Hebert et al. 1996). To control the selectivity of the interaction, a myc-tagged M2 muscarinic Ach receptor was also co-expressed with HA- $\beta_{2} \mathrm{AR}$, and these two could not be co-immunoprecipitated.

With this technique, the cells expressing the two receptors are solubilized and the lysate is incubated with an antibody directed against one of the receptors, or the epitope tag fused to the receptor. The complex is bound to an appropriate medium, electrophoresed, blotted, and visualized using an antibody 
against the other receptor of interest, or its appropriate tag, displaying the GPCRs which form oligomers. The whole process is usually performed in reverse as well, immunoprecipitating with the second antibody and immunoblotting with the first, in order to confirm the specificity and reciprocity of the interaction. However, in many cases, glycosylation of GPCRs prohibits the estimation of the molecular weight of the receptor, and the interacting GPCRs are detected as higher molecular weight complexes. In such cases, the observed interaction may be due to the in vivo formation of larger molecular complexes, therefore in many cases co-immunoprecipitation is not appropriate to draw a conclusion about direct interactions between receptor molecules.

There are a great number of studies documenting the homo- and hetero-oligomerization of different GPCRs using this or similar methods (reviewed in Kroeger et al. (2003)). Some studies suggested a marked specificity of the interaction, e.g. $\kappa$-opioid receptors (OR) dimerized with the $\delta$-OR, but not with the $\mu$-OR (Jordan \& Devi 1999), others showed a promiscuous dimerization, such as the $5 \mathrm{HT}_{1 \mathrm{~A}}$ serotonin receptor, which dimerized with distantly related GPCRs (Salim et al. 2002), and there were negative findings as well, for example the $\mathrm{N}$-formyl peptide receptor was shown not to form homodimers (Gripentrog et al. 2003). Immunoprecipitation can be used to detect oligomeric GPCR complexes, as shown by a study on M2-AchR, where three differently epitope-tagged forms of the receptor (using FLAG[DYDDDDK]-, HA-, and myc-tags) were co-expressed in, and co-immunoprecipitated from Sf 9 cells (Park \& Wells 2004). This paper suggested the existence of trimeric or higher order complexes, co-existing with monomeric receptors, which were also observed.

While co-immunoprecipitation is a commonly used method for the detection of GPCR oligomers, it does have several drawbacks, mainly relating to the lysis and solubilization steps. First, it requires the solubilization of the cells; therefore, it obviously cannot be used to study interactions in living cells. Second, the highly hydrophobic nature of the seven TM domains makes solubilization using detergents a difficult task and GPCRs can form aggregates during this step (Ramsay et al. 2002, Salim et al. 2002). One approach to control this phenomenon is to mix the membranes prepared from cells individually expressing one receptor or the other, and solubilize them, in which case no co-immunoprecipitation should be observed (Jordan \& Devi 1999). However, the problem may persist if the aggregation occurs during the solubilization process due to inappropriate detergent concentration (Chabre \& le Maire 2005). On the other hand, using too much detergent may disrupt the existing interactions between receptors. Another possibility is to use a membrane-impermeable cross-linking agent before the solubilization, as this can stabilize preformed oligomers and demonstrate that they existed before the lysis (Hebert et al. 1996, Cvejic \& Devi 1997). However, the production of free sulfydryl groups during the lysis can also lead to artificial associations independent of receptor oligomerization. This can especially happen when reducing agents such as dithiothreitol or 2-mercaptoethanol are present in the solubilization buffer, therefore capping agents such as iodoacetamide are often used to prevent this. The third problem is also related to the use of detergents, as incomplete solubilization can result in small remaining membrane patches in the supernatant, which may contain both co-expressed GPCRs that are not actually physically in contact. To prevent this, it is necessary to ensure the production of a fully soluble fraction, which can be achieved by thorough centrifugation after detergent extraction, for at least $60 \mathrm{~min}$ and over $100000 \mathrm{~g}$ (Gines et al. 2000). Quite often, the centrifugation is only done in a microcentrifuge producing around $14000 \mathrm{~g}$ and for a shorter time (Salim et al. 2002). Lacking the necessary equipment for this step, it has been suggested that passage of the lysate through a $0.22 \mu \mathrm{m}$ filter may be sufficient to remove the remaining membrane fragments (Milligan \& Bouvier 2005). An additional problem is caused by the glycosylation of some GPCRs, which can produce artificial aggregation of the receptors during the boiling step used to disrupt the immunoglobulin complexes in immunoprecipitation studies. This problem can be reduced by disrupting the complexes at lower temperatures (Smith et al. 1998).

Another major problem arises from the high levels of overexpression often used in these types of experiments. Such artificial levels may induce interactions which would not happen in a physiological environment. This can potentially be avoided by using cell lines stably expressing the studied receptors at a low level, or by changing the strong promoter of the expression vector to a weaker one (e.g. herpes simplex virus thymidine kinase promoter, providing a low-level constitutive expression), or by using an inducible expression system. Perhaps the physiologically most relevant information could be gained from cell lines or tissues endogenously expressing the studied GPCRs. Indeed, one of the greatest advantages of co-immunoprecipitation is that it can be used to directly detect receptor oligomers in ex vivo tissue samples, as it was demonstrated for example in the case of the GABA $\mathrm{B}_{\mathrm{B}}$ and $\mathrm{GABA}_{\mathrm{B} 2}$ receptors (Kaupmann et al. 1998). However, a major obstacle to study GPCR oligomerization in endogenously expressing cells can be attributed to the paucity of quality antibodies against receptors. Specificities of antibodies against some GPCRs are debated (Smith et al. 1998, Thomas 1999, Fredholm et al. 2007). As mentioned in a recent review, it is very difficult to raise useful antibodies to GPCRs, which may be a consequence of the short length and constrained conformation of the extracellular loops, and the main problem with them is the high incidence of false positivity (Fredholm et al. 2007). Consequently, it is possible that some findings regarding receptor localization or oligomerization in native tissues may eventually turn out to be artifacts caused by nonspecific interactions of these antibodies.

Although co-immunoprecipitation may serve as a starting point to analyze oligomerization of GPCRs in native tissues, considering the methodical difficulties, such as selection of the appropriate antibody, the detergent and its concentration, additional methods should be used to verify the detected interaction. 


\section{Resonance energy transfer (RET)}

The development of techniques based on RET, and their application to the investigation of interactions between GPCRs, revolutionized the field of receptor oligomerization. These methods are able to sensitively detect protein-protein interactions in live cells, and in real-time, allowing monitoring of the kinetic and dynamic properties of GPCR complexes (Pfleger \& Eidne 2005).

RET is the nonradiative transfer of energy from a donor molecule to an acceptor molecule as a result of electromagnetic dipole-dipole coupling (Förster 1948). In the case of fluorescence RET (FRET), the energy donor is a fluorescent molecule, excited by exposure to light of a characteristic wavelength, transferring the emitted energy to a fluorescent acceptor molecule (Fig. 2A). The donor molecule can also be an enzyme, Renilla luciferase (Rluc), which causes energy to be released upon oxidation of its substrate, coelenterazine to coelenteramide. The resulting energy transfer to a fluorescent acceptor molecule is called bioluminescence RET (BRET; Fig. 2B).

There are several prerequisites for RET: first, the emission spectrum of the donor molecule should significantly overlap with the excitation spectrum of the acceptor molecule; second, both the donor and the acceptor should be properly oriented relative to each other; and third, they should be in close molecular proximity, effectively $<100 \AA$. As the efficiency of the energy transfer is inversely proportional to the 6th power of distance between the dipoles, this method is especially suited to detect real interactions between proteins, opposed to simple co-localization studies, which are limited by the low spatial resolution of light microscopy. However, the dependence of RET on the proper orientation of the dipoles means that the donor and the acceptor molecules must have a significant degree of freedom in their movement, to make sure that their relative orientation allows the development of RET in at least part of the time. In the case of GPCR fusion proteins, this freedom of movement can be restricted which may impair the RET efficiency. This means that two tagged proteins may fail to produce a RET signal even if they interact with each other. To avoid this problem, it may be necessary to design fusion proteins with different linker sequences (length and composition) and test them for RET.

FRET and BRET can be measured on cell populations by scanning spectroscopy or an appropriate microplate reader or on single cells by microscopy. Microscopy is often used to detect FRET, while BRET is usually measured in plate readers. A great number of GPCRs has been reported to homo- or hetero-oligomerize using these techniques (reviewed in Pfleger \& Eidne (2005)).

\section{FRET}

The green fluorescent protein (GFP) isolated from the jellyfish Aequorea victoria, and its variants are important tools in cell biology, allowing the monitoring of different tagged proteins in living cells (Chudakov et al. 2005). The altered spectral properties of these proteins allow the selection of FRET pairs, of which the most widely used is the cyan fluorescent protein (CFP) as donor and the yellow fluorescent protein (YFP) as acceptor. In this case, CFP can be excited with blue light (around $430 \mathrm{~nm}$ ), and YFP emission can be observed in the yellow range (around $530 \mathrm{~nm}$; Fig. 2A). This was the combination used in the first application of the FRET method to study GPCR oligomerization - in this case, the fusion proteins were constructed as C-terminal fusions to a truncated form of the yeast $\alpha$-factor receptor, lacking their cytoplasmic C-terminal regulatory domains (Overton \& Blumer 2000). Efficient FRET between the receptors due to stable association rather than a collisional interaction was demonstrated in intact cells and membranes. The equilibrium between monomers and oligomers was unaffected by binding of agonist, antagonist, or G-protein heterotrimers. When the tags were fused to the full-length receptors, no FRET signal was detected, which indicated the dependence of FRET on the interfluorophore distance, orientation or mobility.

While the CFP/YFP donor/acceptor pair is the most widely used combination for the detection of FRET between GPCRs, other fusion protein pairs can also be used for this purpose, for example: CFP/GFP (Stanasila et al. 2003), GFP/ DsRed (Dinger et al. 2003), GFP/YFP (Canals et al. 2003), and YFP/red fluorescent protein (RFP; Latif et al. 2001). Alternatively, fluorophores (e.g. fluorescein/rhodamine) conjugated to antibodies can also be used. The antibodies can be directed against epitope tags incorporated into the receptor (Rocheville et al. 2000), or a receptor-specific primary antibody can be used together with a fluorophoreconjugated secondary antibody (Patel et al. 2002a). This method allows endogenously expressed GPCRs to be studied, which can be an advantage of FRET over BRET, but it depends on the availability of a suitably specific antibody against the receptor.

There are several factors that complicate the interpretation of FRET studies. First, the light used to activate the donor molecule may directly excite the acceptor as well. Second, the donor molecule's emission may leak through into the channel used to detect the emission of the acceptor. Third, the FRET efficiency is affected by the expression levels of the donor and the acceptor molecules, while autofluorescence and photobleaching can further complicate the measurements. To overcome the above problems, appropriate correction factors should be used, which can be calculated from separate measurements of the fluorophores, as it was described e.g. in a study regarding the homo-oligomerization of the $\mathrm{C}_{5 \mathrm{a}}$ complement factor receptor (Floyd et al. 2003).

FRET can be measured on populations of cells (either in suspension or adherent), but a major advantage of this technique is that it can be combined with microscopic imaging, using both widefield and confocal microscopes. This allows the study of subcellular compartments, and makes it possible to limit the data acquisition e.g. to the plasma 
A
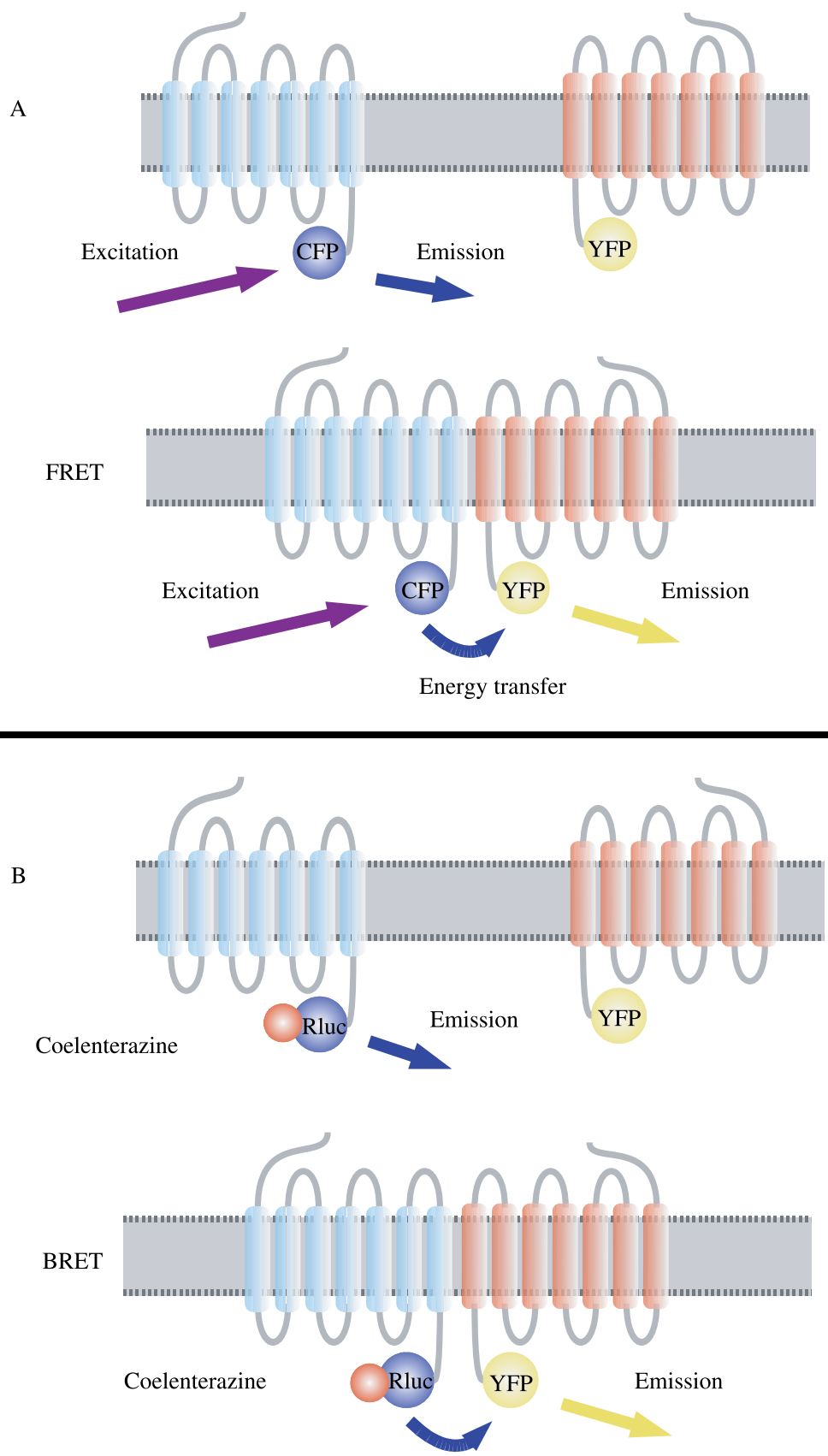

Energy transfer

Figure 2 Illustration of the principle of resonance energy transfer methods. (A) In the case of FRET, a donor fluorophore (in this case CFP) is excited with an external light source, resulting in the emission of blue light, if there is no acceptor molecule nearby (upper panel). If an appropriately oriented acceptor molecule (in this case YFP) is in close proximity $(<100 \AA)$, FRET occurs resulting in the emission of a yellowshifted light (lower panel). (B) In the case of BRET, the donor molecule is the Rluc enzyme, which, upon oxidation of coelenterazine, emits a blue light (upper panel). If the donor is in molecular proximity with an acceptor molecule (in this case YFP) resonance energy transfer occurs, which leads to emission of the light characteristic of the acceptor molecule (lower panel).

membrane. This can be particularly advantageous in the case of GPCR oligomerization, if one would like to separate the oligomerization that occurs during biosynthesis (in the endoplasmic reticulum (ER) and the Golgi) from that on the cell surface (Herrick-Davis et al. 2004). The direct confocal measurement of FRET on live cells also needs correction factors to be used. A method has been developed for this correction, which uses online corrective 
measurements to optimize the detection of FRET in the case of the CFP/YFP pair (van Rheenen et al. 2004). Imaging can also be combined with various photobleaching approaches, discussed below, which increase the sensitivity of FRET detection.

However, not all FRET studies regarding GPCR oligomerization support the existence of oligomers. In a recent paper, a modified version of FRET microscopy was used to study the distribution of neurokinin-1 receptor (NK1R) on the plasma membrane (Meyer et al. 2006). This technique, called acyl carrier protein labeling, allows the posttranslational attachment of different fluorophores to the studied protein in living cells, the ability to selectively label receptors on the cell surface, and control of the donoracceptor ratio. Combining this method with single-cell FRET measurements, the authors excluded the presence of constitutive or ligand-induced homodimers or oligomers of NK1Rs, and revealed that the monomeric receptors concentrated in microdomains, which constituted about $1 \%$ of the cell membrane and were sensitive to cholesterol depletion.

While most of the RET-based techniques are generally unable to determine whether the quaternary structure is restricted to dimers, or higher-order oligomers also exist (Milligan \& Bouvier 2005), there are advances in this field which help to overcome this problem. The FRET methodology can be extended to follow the energy transfer through three different molecules in a sequential manner (e.g. CFP/YFP/RFP), which is called three-chromophore FRET or 3-FRET (Galperin et al. 2004). Using this method, it was recently shown that the $\alpha_{1 \mathrm{~B}}$-adrenergic receptor is able to form oligomeric rather than only simple dimeric complexes in living cells (Lopez-Gimenez et al. 2007).

\section{Photobleaching FRET (pbFRET)}

Photobleaching is an intrinsic property of a fluorophore, characterized by the fading of the fluorescence, which is caused by an irreversible photochemical destruction of the molecule upon continuous exposure to the excitation light. While this phenomenon usually hampers fluorescent measurements, it can be used for the detection of RET, as the rate of photobleaching is comparable to that of FRET (i.e. on the nanosecond time scale), and it always occurs from the excited state of the fluorophore; therefore, this process effectively competes with RET. Either donor or acceptor pbFRET can be measured and these techniques allow the direct demonstration of FRET without using the numerous correction factors needed for conventional FRET studies.

In the case of donor pbFRET, the donor fluorophore is photobleached by an intense illumination, and its fluorescence is measured in the absence and presence of the acceptor. If the two molecules are close enough for RET to occur, it competes with the photobleaching process, which can be measured as a decrease in the rate of photobleaching, shown by an increase in the photobleaching time constant.
This technique has been used to demonstrate the homodimerization of the human somatostatin receptor (SSTR) subtype 5 (SSTR5; Rocheville et al. 2000). N-terminally HA-tagged SSTR5s were expressed in $\mathrm{CHO}$ cells, and pbFRET was measured between fluorescein- and rhodamineconjugated anti-HA antibodies. In cells expressing high levels of SSTR 5 on the membrane $\left(B_{\max }=800 \pm 90 \mathrm{fmol} / \mathrm{mg}\right.$ protein), significant constitutive dimerization was observed in the absence of agonist, and it could be further stimulated with agonist treatment. In the case of a cell line expressing a fivefold lower concentration of receptors $\left(B_{\max }=160 \pm\right.$ $30 \mathrm{fmol} / \mathrm{mg}$ protein), the cells displayed insignificant effective FRET efficiencies in the basal state, suggesting that monomers predominate in the absence of agonist when the receptor is expressed at levels in the range of endogenous SSTR concentrations. Agonist treatment resulted in a dosedependent increase in FRET efficiencies, suggesting that oligomerization, or conformational rearrangement of preformed oligomers, is induced by the binding of the agonist. This observation reiterates the importance of physiological receptor expression levels in oligomerization studies (Patel et al. 2002b).

In the case of acceptor pbFRET, donor and acceptor emissions are measured before and after the photobleaching of the acceptor. If the fluorescence of the donor increases after the destruction of the acceptor, this is taken as evidence of FRET occurring between the donor and acceptor fluorophores. This method has been used to demonstrate agonistdependent microaggregation of the GnRH receptors (GnRHR), C-terminally tagged either with GFP or RFP, both in fixed and in live cells (Cornea et al. 2001). Another study used FRET between C-terminal CFP and YFP tags, in addition to co-immunoprecipitation, to show heterodimerization between endothelin A and endothelin B receptors expressed in HEK293 cells (Gregan et al. 2004).

A possible obstacle to the latter type of experiments (i.e. acceptor pbFRET using a CFP/YFP pair) was revealed in a paper in which the photoconversion of YFP into a CFP-like species was observed upon photobleaching of YFP (Valentin et al. 2005). According to this study, during pbFRET experiments, any increase in the CFP channel could arise from either FRET or from YFP to CFP photoconversion. To further complicate the picture, other groups failed to reproduce this phenomenon, and dismissed the idea of YFP photoconversion (Thaler et al. 2006), but a recent paper again confirmed the production of a CFP-like species, and concluded that until more is understood about the nature of this fluorescent by-product, careful controls need to be done for acceptor pbFRET studies involving YFP (Kirber et al. 2007).

\section{(Homogeneous) time-resolved FRET ((h)trFRET)}

Time-resolved FRET is another method designed to avoid some of the problems associated with the measurement of direct FRET intensity. This approach takes advantage of the 
long-lived fluorescence characteristics displayed by certain lanthanide compounds such as terbium or europium. The prolonged fluorescence of these compounds allows the excitation and the detection of emission to be temporally separated, during which time the signal arising from autofluorescence and direct excitation of the acceptor dies down. This technique uses antibodies labeled with europium $\left(\mathrm{Eu}^{3+}\right)$ chelate (McVey et al. 2001) or cryptate (Maurel et al. 2004) as donors, and allophycocyanin- or Alexa Fluor 647labeled antibodies as acceptors. The use of antibodies ensures that only the receptors on the cell surface are detected, but it also serves as a limitation, since, as described above, development of antibodies against GPCRs is often difficult, and specific antibodies are not available for many of these receptors. However, the antibodies can be directed against epitope tags incorporated into the receptor constructs, or receptor-specific primary antibodies can be used in conjunction with labeled secondary antibodies. The $\mathrm{Eu}^{3+}$ label is excited at $320 \mathrm{~nm}$, and the emissions are monitored after a $50 \mu$ s delay for 200-400 $\mu$ s at $615 \mathrm{~nm}$ for $\mathrm{Eu}^{3+}$ emission and at $665 \mathrm{~nm}$ for RET. As the donor dipole is effectively rotating in the chelate or cryptate, the emission is unpolarized, which greatly reduces the orientation dependence of FRET, making distance determination more accurate.

While the trFRET measurements usually include washing steps to remove unbound antibodies, e.g. in the study demonstrating $\delta$-OR homo-oligomers at the plasma membrane (McVey et al. 2001), homogenous assays without washing steps are also possible, thanks to the high sensitivity of this method and to the low concentration of antibodies required (Maurel et al. 2004). This htrFRET approach is particularly suited to high-throughput screening protocols.

\section{Fluorescence lifetime imaging (FLIM)}

The fluorescence lifetime of a fluorophore is defined as the average time that a molecule remains in an excited state before returning to the ground state. This is a property of the individual fluorophore; it is unaffected by the change in probe concentration or excitation intensity but is influenced by changes in the cellular environment, such as changes in $\mathrm{pH}$ and ion concentration, and is also affected by FRET. In a FRET-FLIM approach, the occurrence of FRET is measured by monitoring the change in donor lifetime in the presence and absence of acceptor, and if FRET occurs, the donor lifetime is shortened. While it requires the use of specialized equipment, FRET-FLIM has some significant advantages over intensity-based FRET approaches (Wallrabe \& Periasamy 2005), and is particularly suited for in vivo studies because it requires a low excitation intensity (avoiding photobleaching) and low levels of fluorescent proteins can be detected. The two major instrumental methods for measuring fluorescence lifetimes are the frequency domain and the time domain measurements. Either method can be used in one-photon or two-photon FRET-FLIM microscopy, the latter being more suited for the imaging of live cells thicker specimens.
The FRET values from GFP fluorescence decay can be calculated with spatial resolution, which enables the proportion of interacting partners to be determined, as it was demonstrated in the study of homo- and heterooligomerization of $\beta$-arrestin molecules in living cells (Storez et al. 2005).

\section{FRET between ligands}

Another possible method to study GPCR oligomerization involves the use of ligands conjugated to fluorophores. In a paper investigating the self-association of luteinizing hormone (LH) receptors, FRET was measured between LH or human chorionic gonadotropin (hCG) molecules labeled with fluorescein and rhodamine (Roess et al. 2000). The observed FRET was higher between LH receptors binding the fluorescent hCG molecules, than between the ones binding LH molecules. In another study, fluorescein- and Texas Red-conjugated somatostatin molecules were used to show that SSTR homo- and hetero-oligomers must be occupied by the two fluorescent ligand molecules, and the ligands must reside within $100 \AA$ of each other (Patel et al. 2002a). This technique can be potentially used to study interactions between endogenous receptors, particularly regarding the recent advances in the various available fluorophores (Giepmans et al. 2006).

\section{BRET}

BRET is a naturally occurring phenomenon in several marine animals, such as the jellyfish $A$. victoria and the sea pansy Renilla reniformis. These organisms produce a substrate, coelenterazine, which is enzymatically oxidized into coelenteramide, with the subsequent release of bioluminescent light. In $A$. victoria, the reaction is catalyzed by the aequorin enzyme, resulting in a peak emission at $486 \mathrm{~nm}$, while in $R$. reniformis the Rluc enzyme produces light with an emission maximum at $480 \mathrm{~nm}$. In both organisms, the energy is transferred to the appropriate GFP molecule (Aequorea or Renilla), which results in the emission of green light (emission maximum at $509 \mathrm{~nm}$ ) instead of the original blue produced in the enzymatic reaction (Hastings 1996).

The first application of BRET to the study of protein interaction used Rluc as energy donor, and enhanced YFP (eYFP) as acceptor to demonstrate the dimerization of a circadian clock protein, KaiB, expressed in E. coli $(\mathrm{Xu}$ et al. 1999). In this configuration, the peak emission of eYFP can be detected at $\sim 530 \mathrm{~nm}$, and the Rluc at $480 \mathrm{~nm}$. The method was quickly applied to the investigation of GPCRs, and the data suggested a constitutive homodimerization of human $\beta_{2}$-adrenergic receptors $\left(\beta_{2} \mathrm{AR}\right)$ expressed in HEK293 cells (Angers et al. 2000), in the same year when FRET was first used to study GPCR dimerization (Overton \& Blumer 2000). BRET soon became a widely used method to monitor the interactions of GPCRs (Pfleger \& Eidne 2003), and the (homoand hetero-)dimerization of various receptors were reported (reviewed in Pfleger \& Eidne (2005)). 
In the classical BRET assay $\left(\mathrm{BRET}^{1}\right)$, the substrate is coelenterazine $\mathrm{h}$ (this is a synthetic coelenterazine analogue with increased luminescence intensity compared with the native molecule) and the acceptor is eYFP (Fig. 2B). In this configuration, Rluc and eYFP emit light between 475-480 nm and $525-530 \mathrm{~nm}$ respectively resulting in a relatively poor spectral resolution (difference between donor and acceptor emission maxima) of $45-55 \mathrm{~nm}$. Also, as Rluc produces a broad emission peak that substantially overlaps the YFP emission, the signal to background ratio of the system is suboptimal. In an effort to overcome these problems, the BRET ${ }^{2}$ methodology (Perkin-Elmer, Waltham, MA, USA) uses a coelenterazine derivative called DeepBlueC as substrate, and $\mathrm{GFP}^{2}$ (a modified form of GFP) as acceptor. In this case, the donor emission is at $395 \mathrm{~nm}$ and the acceptor emission is at $510 \mathrm{~nm}$ resulting in a better spectral resolution $(115 \mathrm{~nm})$ and an improved signalto-noise ratio (Ramsay et al. 2002). However, it should be noted that the absolute signals produced are much lower in this configuration than in $\mathrm{BRET}^{1}$, which decreases the detection sensitivity, and they are decaying at a very fast rate, which makes $\mathrm{BRET}^{2}$ impractical for kinetic measurements. It is possible to monitor the two kinds of BRET simultaneously in the same cells (Perroy et al. 2004), which may be adapted to study the stoichiometry of GPCR oligomerization. For long-term kinetic studies, a new 'extended' BRET (eBRET) methodology may be used (Pfleger et al. 2006). This technique uses a protected form of coelenterazine $h$, termed EnduRen (Promega), which is metabolized to coelenterazine $h$ by esterases within cells, allowing the monitoring of protein-protein interactions for several hours in cells kept at $37^{\circ} \mathrm{C}$, in the presence of serum (which greatly increases the autoluminescence of conventional coelenterazine $h$ and DeepBlueC).

BRET has several advantages and some disadvantages when compared with FRET (Boute et al. 2002). Most of the advantages come from the lack of an excitation light source: excitation light can damage live cells, induce autofluorescence, and cause photobleaching of the fluorophores. Moreover, the analysis of FRET signal is complicated by the direct excitation of the acceptor molecule, resulting in a higher background signal. As this background can be eliminated in BRET, this method is theoretically more sensitive than FRET, which was demonstrated by a noncompetitive homogenous bioluminescent immunoassay that was ten times more sensitive than a comparable FRET assay (Arai et al. 2001). The disadvantages include the fact that since BRET is always measured between fusion proteins, it can only be performed in recombinant systems. Probably the biggest limitation of this technique is that the low amount of light emitted in the reaction is below the sensitivity of most of the presently available imaging equipment, and thus it cannot easily provide information about the subcellular localization of the observed protein-protein interactions. This can be especially interesting in the case of GPCR oligomerization, as oligomerization can happen early in the biosynthetic pathway, on the plasma membrane, or in endocytic vesicles. The obligate use of expressed proteins can further aggravate this problem, because overexpression could conceivably induce nonspecific interactions in the ER and the Golgi, or between misfolded proteins targeted to degradation. With recent advances in the field of imaging instruments, this is now beginning to change, as now not only single-cell BRET signals can be detected, as it was demonstrated for $\beta_{2} \mathrm{AR}$, and melatonin MT1 and MT2 homodimers (Ayoub et al. 2002), but even subcellular BRET imaging was shown using the agonist-dependent interaction between the V2 vasopressin receptor and $\beta$-arrestin 2 as a proof of principle (Coulon et al. 2008).

As the movement of membrane proteins is restricted to two dimensions, opposed to cytosolic proteins, it is possible that two expressed GPCRs display an aspecific BRET signal due to 'molecular crowding' in the membrane. This problem is especially worrying in the case of heterologous systems, where the expression levels can be very high, and the ER and Golgi may contain large amounts of proteins at various stages of maturation, possibly contributing significantly to the detected BRET signal (Terrillon et al. 2003). This necessitates the use of appropriate negative controls. Another question is the relative affinity of the interacting partners, which cannot be determined from BRET experiments employing a single concentration of Rluc- and YFP-tagged GPCRs, because the intensity of a BRET signal depends on both the distance and the orientation of the dipoles. An answer to these questions was provided in the form of quantitative BRET experiments (Mercier et al. 2002). In these kinds of studies, the cells are transfected with different concentrations of donor- and acceptor-linked receptors (usually a fix amount of donor and increasing amounts of acceptor), and the BRET signal is plotted as a function of the acceptor/donor ratios, optimally calibrated to cell surface receptor expression derived from radioligand binding. In the case of a specific interaction, the detectable BRET should increase with the increasing acceptor/donor ratios until a saturation level is reached, representing the state when every donor molecule is interacting with an acceptor. The hyperbolic 'saturation BRET' curves that can be plotted from such an experiment resemble those of classical saturation ligand-binding studies. The acceptor/donor ratio resulting in half maximal BRET signal $\left(\mathrm{BRET}_{50}\right)$ is characteristic of the affinities of the interacting partners, and thus can be used to compare the propensity of the studied GPCRs to form oligomers (Ayoub et al. 2004). In the case of nonspecific interaction, the so-called 'bystander' BRET signal displays a quasi-linear relationship with the increasing acceptor/donor ratio, which may saturate at a very high ratio. These experiments showed that oligomerization can happen at physiologically relevant expression levels. The data from saturation curves can also be used to gain information about the oligomerization states of the receptors (Mercier et al. 2002), using models of energy transfer quenching (Veatch \& Stryer 1977). The specificity of a given interaction can also be studied using BRET competition experiments in which the BRET signal detected between two interacting proteins at a given acceptor/donor 
ratio can be diminished by the co-expression of untagged partners, but not with a noninteracting protein (Ayoub et al. 2002). A third way to differentiate between specific and nonspecific interactions is to vary the expression levels of the tagged receptors at a fixed acceptor/donor ratio, in which case the specific partners display a constant BRET signal over a wide expression range, while the nonspecific interaction increases with the levels of the receptors (Mercier et al. 2002).

Recently, a 'rigorous experimental framework' has been proposed for BRET experiments studying GPCR oligomerization, which, among others, suggested that a lot of previously reported interaction was actually nonspecific and that saturation BRET experiments should be done in a way that keeps the total receptor number constant (James et al. 2006). A conclusion of the paper was that the studied family A GPCRs exemplified monomeric behavior. This study raised a considerable debate (Bouvier et al. 2007) and experimental challenge (Salahpour \& Masri 2007). While the need for proper controls and careful experimental design cannot be overestimated, BRET experiments remain a very powerful tool for the detection of GPCR oligomerization (Marullo \& Bouvier 2007). However, we have to keep in mind that although homo- and heteromeric interactions were detected between a number of different GPCRs using RET methods, these methods actually detect molecular proximity (and orientation). Therefore, although a properly controlled RET signal indicates molecular proximity between the studied molecules, based on these experiments it is difficult to conclude about its structural bases. RET signals may reflect the presence of dimers or oligomers, but it is very difficult to definitely rule out, using these methods, the clustering of receptors in membrane microdomains, where molecular complexes are organized by interacting molecules without the direct interaction between receptor molecules.

\section{Bimolecular fluorescence complementation (BiFC)}

$\mathrm{BiFC}$ is an alternative approach to the detection of proteinprotein interactions in living cells (Kerppola 2006). It is based on the reconstitution of a fluorescent protein molecule upon reassociation of its two nonfluorescent fragments ( $\mathrm{Hu}$ et al. 2002). For example, if YFP is split into N-terminal (172 amino acid residue) and C-terminal (67 amino acid residue) fragments, neither of these molecules displays fluorescent properties when expressed alone. Co-expression of the fragments linked to interacting proteins allows the partial reformation of YFP with the concomitant appearance of the fluorescent signal. The main advantage of this method is that the interaction can be detected with a simple fluorescence microscope and therefore a specialized imaging equipment is not required. Also, the orientation requirements of the fragments are less stringent when compared with FRET. A limitation of the method is the time required for the fragments to form a functional protein, which means that this method is not really suitable to detect fast changes in the interaction between proteins. This method was used to detect homodimers of the $\alpha_{1 \mathrm{~B}}$-adrenergic receptor (Lopez-Gimenez et al. 2007). An extension of this technique, called multicolor fluorescence complementation, uses fragments from different fluorescent molecules which form complexes with distinct spectral properties, allowing the simultaneous visualization of multiple protein interactions (Hu \& Kerppola 2003).

GPCRs often interact with different accessory proteins that modulate their function (Bockaert et al. 2004, Parameswaran \& Spielman 2006). A combination of BiFC with BRET was recently described to analyze the stoichiometry of such complexes in the case of the calcitonin gene-related peptide receptor (Heroux et al. 2007), which requires the association with the single TM receptor activity-modifying protein-1 (RAMP1) to reach the cell surface and be active. The authors used these techniques to elegantly demonstrate that the functional receptor at the plasma membrane consists of at least two molecules of the GPCR and one RAMP1 molecule. This approach can also be used to study the existence of higher-order GPCR complexes.

\section{Structural studies}

The most tangible evidence for GPCR dimerization came from atomic force microscopy (AFM) studies of membranes from murine rod outer segment (ROS) disks, which demonstrated complex in situ quaternary organization of rhodopsin molecules (Fotiadis et al. 2003a, Liang et al. 2003). The pictures showed paracrystalline arrays and raft-like structures made up from double rows of rhodopsin molecules, with individual dimers breaking off at the end of the structures, and occasional monomers. The model of oligomerized rhodopsin derived from these studies and a previously reported structure of bovine rhodopsin (Palczewski et al. 2000) is shown in Fig. 3. The density of the receptors in tightly packed regions was between 35000 and 50000 monomers $/ \mu^{2}$, somewhat higher than that estimated previously (Chabre et al. 2003). However, based on earlier biophysical measurements and the concern over possible phase separation between proteins and lipids during sample preparation, it has been suggested that the observed structure does not correspond to the native conformation of nonactivated rhodopsin in dark-adapted rods, but is instead an artifact of the preparation process (Chabre et al. 2003, Chabre \& le Maire 2005). Beyond this controversy regarding the in vivo relevance of the rhodopsin structure observed by AFM (Chabre et al. 2003, Fotiadis et al. 2003a,b), it should be kept in mind that rhodopsin molecules constitute more than $90 \%$ of all disk membrane proteins, which cannot be said of GPCRs in general, and consequently this structure may only be the hallmark of this specialized compartment. The above studies were repeated using ROS membranes isolated from mice heterozygous for the rhodopsin gene deletion, and the observed structure and receptor density showed no major changes compared with the wild-type mice, while the 


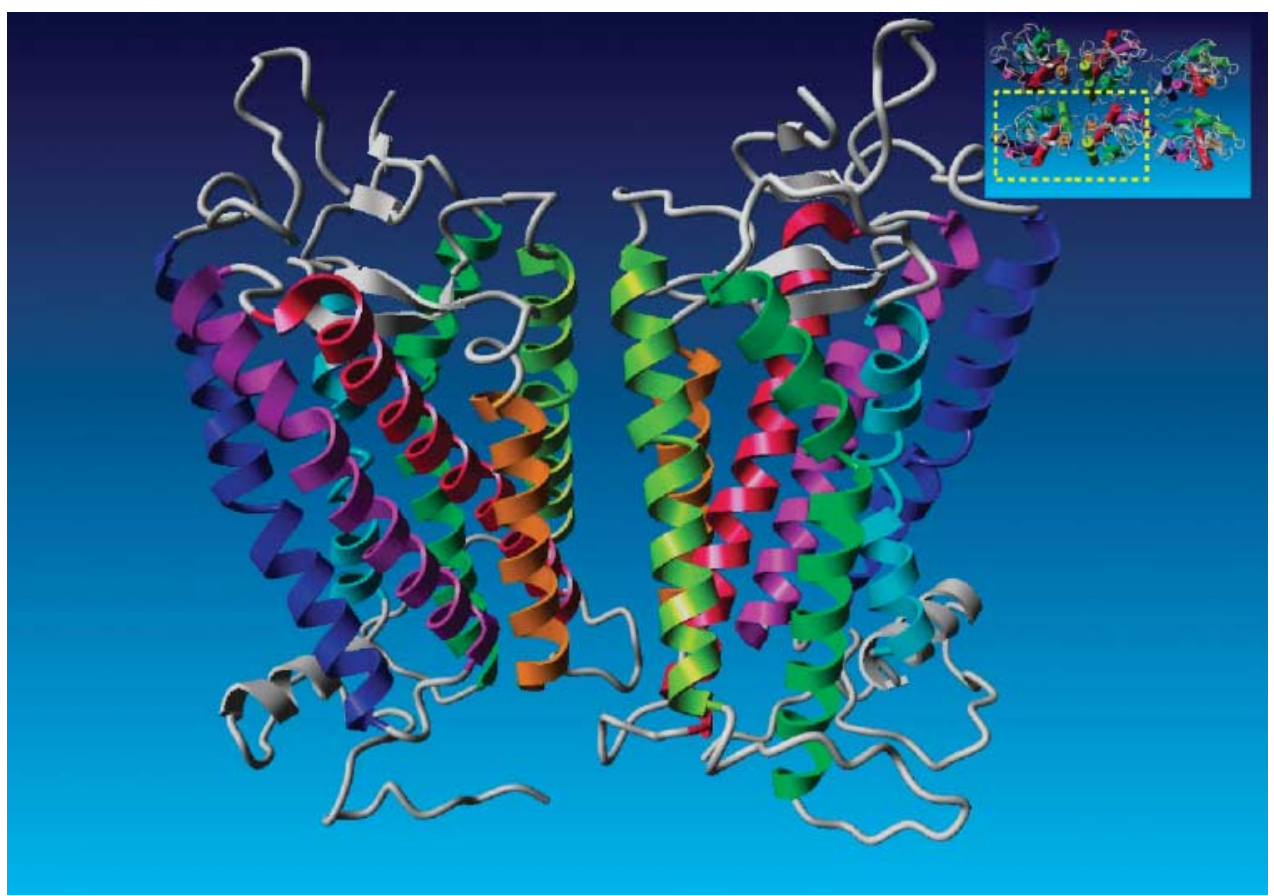

Figure 3 Model of rhodopsin oligomers deposited at the Protein Data Bank (code 1N3M) based on data obtained from atomic force microscopy (Liang et al. 2003) and the crystal structure of bovine rhodopsin (Palczewski et al. 2000). In the insert, dashed lines indicate the rhodopsin dimer, which is enlarged in the figure. In the dimer, interdimeric contacts occur at helices 4 and 5.

volume of the ROS was smaller (Liang et al. 2004). In an artificial system, rhodopsin was able to self-associate into dimers even at a low receptor density, as assessed by FRET measurements, which argues for the dimerization of rhodopsin at lower surface densities (Mansoor et al. 2006).

The high-resolution crystal structures of rhodopsin do not show a consistent dimerization of the rhodopsin molecule. The first high-resolution crystallographic structure showed rhodopsin dimers in biologically irrelevant antiparallel organization (Palczewski et al. 2000), and other studies reported similar arrangements of rhodopsin crystals ( $\mathrm{Li}$ et al. 2004). Although a recent study using new crystal forms of rhodopsin suggested an oligomerization contact site, the surface of this site is too small to predict stable interactions and different from the site predicted by a model based on the AFM studies, and it was suggested that it may mediate the secondary contacts between the rows of rhodopsin molecules in the AFM images (Lodowski et al. 2007). Very recently, the crystal structure of the human $\beta_{2} \mathrm{AR}$ became available. Rasmussen et al. (2007) reported the structure of the receptor, which was crystallized in a lipid environment, bound to an inverse agonist in complex with a monoclonal antibody Fab fragment that binds to the third intracellular loop. In this crystal, the $\beta_{2} \mathrm{AR}$ was found to be monomeric, in contrast to the reported rhodopsin crystal structures. In another study, the crystallization of the receptor was facilitated by inserting T4 lysozyme in place of the third intracellular loop (Cherezov et al. 2007). This structure showed a multilayered arrangement of the receptors, and within each layer, the protein molecules formed arrays of parallel, symmetry-related dimers. The main contact point was between the charged amine group of $\mathrm{Lys}^{60}$ in TM1 and the carboxylate of Glu ${ }^{338}$ in helix 8, a cytoplasmic helix formed in the membrane-proximal part of the tail, roughly perpendicular to the TM bundle, which is thought to be a common feature in all rhodopsin-like GPCRs (Katragadda et al. 2004). Similar associations between receptor molecules have been found in rhodopsin crystal structures as well (Schertler 2005, Salom et al. 2006). However, the dimerization interface of GPCRs is controversial, since other studies suggested different localizations, such as TM6 as the dimer interface for the $\beta_{2} \mathrm{AR}$ (Hebert et al. 1996), TM4 was reported to mediate homodimerization of the D2 dopamine and C5a complement receptors, and TM1 and 2 were implicated in mediating the dimerization of the yeast $\boldsymbol{\alpha}$-factor receptor (reviewed in Kroeger et al. (2003) and Breitwieser (2004)).

\section{Receptor G-protein stoichiometry}

All GPCRs, including rhodopsin, were initially assumed to exist and function as monomers, activating a heterotrimeric G-protein with a 1:1 stoichiometry. Most of the previously available biophysical and biochemical data supported this idea (reviewed in Chabre \& le Maire (2005)). When the AFM 
studies showed dimeric structures in the ROS membranes, it has been suggested that the functional unit may be composed of a rhodopsin dimer coupling to one G-protein (Liang et al. 2003). This model was based on the crystal structure of monomeric rhodopsin (Palczewski et al. 2000) and stated that the cytoplasmic surface of one receptor was too small to interact with all subunits of transducin on its own, while the combined surface of a rhodopsin dimer would provide a good docking site, one protomer interacting with the $\alpha$ - and the other with the $\beta \gamma$-subunits (Filipek et al. 2004). A biochemical analysis of rhodopsin molecules showed that although both activated monomers and dimers were capable of activating transducin, the activation process was faster in the case of organized dimers (Jastrzebska et al. 2006), further supporting this model (Fotiadis et al. 2006). In the case of the B4 leukotriene type 1 (BLT1) receptor, a similar pentameric assembly was proposed, composed of a BLT1 dimer and the heterotrimeric G-protein (Baneres \& Parello 2003).

However, this concept has been challenged based on arguments that the crystal structures used for the construction of the above model are not sufficiently complete, especially regarding the interaction site between the receptor and the G-protein, and a model was proposed, in which a monomeric GPCR acts as the functional unit (Chabre \& le Maire 2005). Recent data seem to be supporting the latter hypothesis, including a computational analysis, which states that monomeric dark rhodopsin holds the molecular determinants for transducin recognition (Dell'Orco et al. 2007), and a biochemical study in which monomeric rhodopsin was sufficient for fully functional transducin activation (Ernst et al. 2007).

Using very similar approaches, data from two workgroups further confirm the validity of a 1:1 stoichiometry between the GPCR and its G-protein. Transducin activation was studied in nanoscale lipid bilayers (Nanodisc), containing either one or two rhodopsin molecules and one transducin (Bayburt et al. 2007). It was shown that in this system a rhodopsin monomer is fully capable of highly efficient coupling to transducin, and that in Nanodiscs containing two receptors, only one was able to form a stable metarhodopsin II-transducin complex. In another paper, a monomeric $\beta_{2} \mathrm{AR}$ was incorporated into a reconstituted high-density lipoprotein phospholipid bilayer particle together with the stimulatory heterotrimeric G-protein, $G_{s}$. The monomeric $\beta_{2}$ AR efficiently activates $G_{s}$ in this system and displays GTP-sensitive allosteric ligand-binding properties, suggesting that a monomeric receptor in a lipid bilayer is the minimal functional unit necessary for signaling, and that the cooperativity of agonist binding is due to G-protein association with a receptor monomer and not receptor oligomerization (Whorton et al. 2007).

It has also been suggested that the arrestin molecule has the appropriate size and shape to interact with a rhodopsin dimer, and consequently this interaction would also have a 2:1 stoichiometry (Liang et al. 2003, Fotiadis et al. 2006). However, recent in vivo and in vitro experiments also argued against this hypothesis, supporting the 1:1 stoichiometry between the receptor and arrestin (Hanson et al. 2007).

\section{Functional studies}

Perhaps the most important pieces of evidence in support of the concept of receptor dimerization and/or oligomerization came from functional studies. Several studies have reported co-internalization and modulation of the signaling activity of hetero-oligomerized GPCRs (for citations see Terrillon \& Bouvier (2004), Prinster et al. (2005)). However, demonstration of the co-internalization of GPCRs has a limited value as an evidence for oligomerization. The internalization of receptors requires the association of the receptor with larger molecular complexes, such as the clathrin coat or caveolae, and association of non-oligomerized 'bystander' receptors with components of these complexes, leading to its co-internalization with another activated receptor, is difficult to rule out. Similarly, activation of the signal transduction of a receptor with another GPCR can occur with a number of different mechanisms, caused by the signaling of the activated receptor, rather than direct interactions due to oligomerization. However, studies on the trafficking of newly synthesized receptors, and modulation of the ligand binding by co-expressed receptors provided interesting findings in favor of the concept of receptor oligomerization.

\section{Studies with family C GPCRs}

The functional evidence, which gave a wide recognition to the concept of GPCR dimerization was the discovery that the function of metabotropic $\mathrm{GABA}_{\mathrm{B}}$ receptors absolutely requires heterodimerization of $\mathrm{GABA}_{\mathrm{B} 1}$ and $\mathrm{GABA}_{\mathrm{B} 2}$ receptors (Jones et al. 1998, Kaupmann et al. 1998, White et al. 1998). It has been demonstrated that $\mathrm{GABA}_{\mathrm{B} 1}$ receptors are unable to reach the cell surface in the absence $G_{A B A}$ 2 receptors, because $\mathrm{GABA}_{\mathrm{B} 1}$ receptors contain an endoplasmic reticulum retention signal, which is masked by heterodimerization with $\mathrm{GABA}_{\mathrm{B} 2}$ receptors (Couve et al. 1998). It is now widely accepted that $\mathrm{GABA}_{\mathrm{B} 1}$ and $\mathrm{GABA}_{\mathrm{B} 2}$ receptors work together as a functional unit in which agonists interact with the $G_{A B A}$ 1 subunit, whereas the $G_{A B A} 2$ subunit is responsible for $\mathrm{G}$-protein activation and efficient trafficking of the heterodimer to the cell surface (Galvez et al. 2001). The in vivo relevance of the functional importance of this interaction is well accepted and supported by a number of findings, including data with $\mathrm{GABA}_{\mathrm{B} 1}$ and $\mathrm{GABA}_{\mathrm{B} 2}$ receptor knockout mice, which demonstrated that the deletion of either gene leads to similar phenotypes and almost complete elimination of all $\mathrm{GABA}_{\mathrm{B}}$-mediated responses (Gassmann et al. 2004, Pin et al. 2007). In some brain areas $\mathrm{GABA}_{\mathrm{B}}$ function is retained after genetic elimination of the $\mathrm{GABA}_{\mathrm{B} 2}$ receptors, which may suggest that the role of $\mathrm{GABA}_{\mathrm{B} 2}$ receptors in functional complementation of 
$\mathrm{GABA}_{\mathrm{B} 1}$ receptors is not exclusive, and other proteins can substitute for this function (Gassmann et al. 2004).

The essential role of heterodimerization in the function of other family $\mathrm{C}$ receptors has also been demonstrated. The functional units of umami and sweet taste receptors are also heterodimers of T1R1 and T1R3, T1R2 and T1R3 receptors respectively and similar to $\mathrm{GABA}_{\mathrm{B}}$ receptors, each of these subunits serve specific functions in terms of ligand recognition and G-protein activation (Nelson et al. 2001, 2002, Xu et al. 2004). The physiological relevance of this heterodimerization was demonstrated in studies using knockout mice, which showed that elimination of the T1R1 and T1R2 gene affects sweet and umami taste recognition respectively, whereas genetic deletion of the T1R3 gene impairs both functions (Damak et al. 2003, Zhao et al. 2003).

\section{Studies with family $A$ and $B$ GPCRs}

Functional data on GPCR dimerization are not limited to family C receptors. Naturally occurring N-terminally truncated variant of the family B pufferfish calcitonin receptor can heterodimerize with the normal receptor protein and can attenuate the ligand-induced intracellular signaling without affecting its plasma membrane targeting and ligand-binding properties, possibly by changing the conformation of the cytoplasmic regions of the receptor that interacts with the G-proteins (Nag et al. 2007). The mechanism may be similar to the one found in the case of GPR50, an orphan GPCR, which has been shown to heterodimerize with, and specifically inhibit the MT1 melatonin receptor (Levoye et al. 2006). It has also been demonstrated that heterodimerization of family A $\alpha_{1 \mathrm{D}}$-adrenoceptors with $\alpha_{1 \mathrm{~B}}$-adrenoceptors is necessary for proper cell surface expression of the $\alpha_{1 \mathrm{D}}$-adrenoceptor (Hague et al. 2004b), and that co-expression and heterodimer formation of $\alpha_{1 \mathrm{D}^{-}}$and $\alpha_{1 \mathrm{~B}^{-}}$ adrenoceptors lead to an altered pharmacological profile of these receptors, which may explain that $\alpha_{1 \mathrm{D}}$-adrenoceptor are pharmacologically undetectable in tissues, which express abundant quantities of its mRNA (Hague et al. 2006).

In most systems dimerization or oligomerization of GPCRs is agonist independent and occurs early during receptor biosynthesis, probably in the endoplasmic reticulum. In some cases, agonist effect on receptor oligomerization has been reported, but these changes may reflect the effects of agonistinduced conformational changes on the stabilization of preexisting oligomers or RET efficiency (Bulenger et al. 2005). However, as detailed above, compelling evidence suggests that heterodimer formation is required for many family $\mathrm{C}$, and some family A receptors, to reach the cell surface. This might be a more general phenomenon since a large number of other GPCRs, such as adrenocorticotropin receptors, adenosine, bitter taste, and olfactory receptors, do not express well in heterologous expression systems (Noon et al. 2002, Clark et al. 2003, Minneman 2007). Although the tissuespecific mechanisms leading to the cell surface expression of these receptors has not been fully elucidated, heterooligomerization with the $\beta_{2}$-adrenergic receptor has been reported to facilitate the cell surface expression of olfactory receptors (Hague et al. 2004a). It is possible that, at least in some tissues, proper expression of these receptors requires the presence of other GPCRs, but the role of other chaperons or chaperon-like proteins cannot be excluded in this process.

Many GPCRs express well in a wide range of heterologous expression systems. Apparently, these receptors do not need hetero-oligomerization to avoid the quality control mechanisms of the endoplasmic reticulum. It has been proposed that oligomerization may be a common requirement for GPCRs to pass quality checkpoints along the biosynthetic pathway, with homo-oligomerization being the general rule, and hetero-oligomerization being a special case for some receptors (Bulenger et al. 2005). Although this hypothesis needs additional experimental validation and other exceptions may exist, it is an attractive hypothesis which can explain the need for hetero-oligomerization for cell surface expression of some receptors, whereas most receptors could reach the cell surface as homo-oligomers. In the latter case the role of homo-oligomerization in cell surface targeting may explain the dominant negative behavior of pathogenic GPCR mutations, which cause intracellular retention of the mutant receptor as well as the co-expressed wild-type receptors and decrease their expression and signaling (Zhu \& Wess 1998). This can result in a dominant transmission of diseases in heterozygotes (Tao 2006), such as in the case of partial thyroid-stimulating hormone (TSH) resistance due to heterozygous inactivating mutations in TSH receptor gene (Calebiro et al. 2005). Such dominant-negative effect can be advantageous as well: a truncated form of the chemokine receptor type 5 (CCR5), CCR $5 \Delta 32$ can oligomerize with the wild-type CCR5 in the ER, causing an intracellular retention of the oligomer (Benkirane et al. 1997). Since CCR5 is a major co-receptor for the human immunodeficiency virus (HIV), individuals carrying this mutation even in a heterozygous form are partially protected from the infection and display a slower progression of the disease. While the role of oligomerization in this effect is not entirely undisputed (Venkatesan et al. 2002), further studies indicated that in addition to CCR 5 , CCR $5 \Delta 32$ can also oligomerize with and reduce the expression of chemokine receptor type 4 (CXCR4), which is also implicated in HIV entry into the cells (Agrawal et al. 2004).

Many GPCRs have alternative splice variants (often truncated forms of the wild-type receptor), and these can also have a regulatory effect on the full-length molecule; a splice variant of the dopamine D3 receptor, D3nf, truncated before the sixth TM, has been shown to oligomerize with the wild-type receptor, thereby reducing its expression (Karpa et al. 2000). The relative expression of D3 and D3nf was found to be different in high and low responders to novelty in an animal model, which may indicate the physiological relevance of this splice variant (Pritchard et al. 2006). 


\section{Studies on ligand binding}

It has been known for a long time that the interaction of GPCRs with other molecules can lead to an allosteric modulation of the ligand binding of the receptor. The 'classical' examples of these modulations are interactions with G-proteins and $\mathrm{Na}^{+}$ions (Catt \& Dufau 1977). However, if GPCRs exist as dimers or oligomers, ligand binding to one receptor may lead to conformational changes which affect the ligand binding of the partner receptor. In case of receptor homo-oligomers, such interactions would be detected as positive or negative cooperativity of the ligand binding. In fact, early studies demonstrated cooperativity of the ligand binding of various GPCRs, such as angiotensin (Sraer et al. 1977), $\beta$-adrenergic (Limbird \& Lefkowitz 1976), opiate (Davis et al. 1977), TSH (Tate et al. 1975), and other (Baxter \& Funder 1979) receptors. However, interpretation of these observations were ignored or considered simply the consequence of receptor-G-protein interaction, since GPCRs were widely regarded as monomeric entities at the time. Mesnier and Baneres have demonstrated an allosteric interaction between protomers of a wild-type and mutant BLT1 receptor upon leukotriene B4 binding using a spectroscopic approach (Mesnier \& Baneres 2004).

Vassart et al. designed a number of experiments to study whether the presence of agonists affects the kinetics of ligand dissociation after an infinite dilution of a pre-bound labeled ligand. They were able to show in all three families of GPCRs, that in case of the receptors that form homooligomers, the presence of unlabeled ligand facilitated the dissociation rate of the tracer (El Asmar et al. 2005, Urizar et al. 2005, Springael et al. 2006, 2007). Under the experimental conditions used in these studies, rebinding of the tracer is unlikely and the observed effects can be attributed to allosteric interactions between the subunits of receptor dimers or oligomers. Interestingly, both agonists and antagonists could evoke faster ligand dissociation (i.e. negative cooperativity), indicating that full receptor activation is not required to cause allosteric interactions between receptor oligomers. Allosteric interactions have also been demonstrated between hetero-oligomerized chemokine receptors (Springael et al. 2006), and studies with $\mathrm{GABA}_{\mathrm{B}}$ receptors also indicate that although the different subunits have specific functions, the other subunit can allosterically stimulate the hormone binding of the $\mathrm{GABA}_{\mathrm{B} 1}$ subunit or the G-protein activation by the $\mathrm{GABAB}_{\mathrm{B} 2}$ subunit (Galvez et al. 2001). These interactions provide evidence for the functional relevance of GPCR dimerization or oligomerization, since these interactions can be demonstrated in native tissues (Springael et al. 2007).

A cross-inhibition of GPCRs also provides indirect evidence to support the concept of receptor oligomerization. Perhaps the most striking example of this effect is the crossinhibition of $\beta$-adrenergic and $\mathrm{AT}_{1}$ angiotensin receptors (Fig. 4), which was independent of allosteric modulation of the ligand binding of these receptors (Barki-Harrington et al.
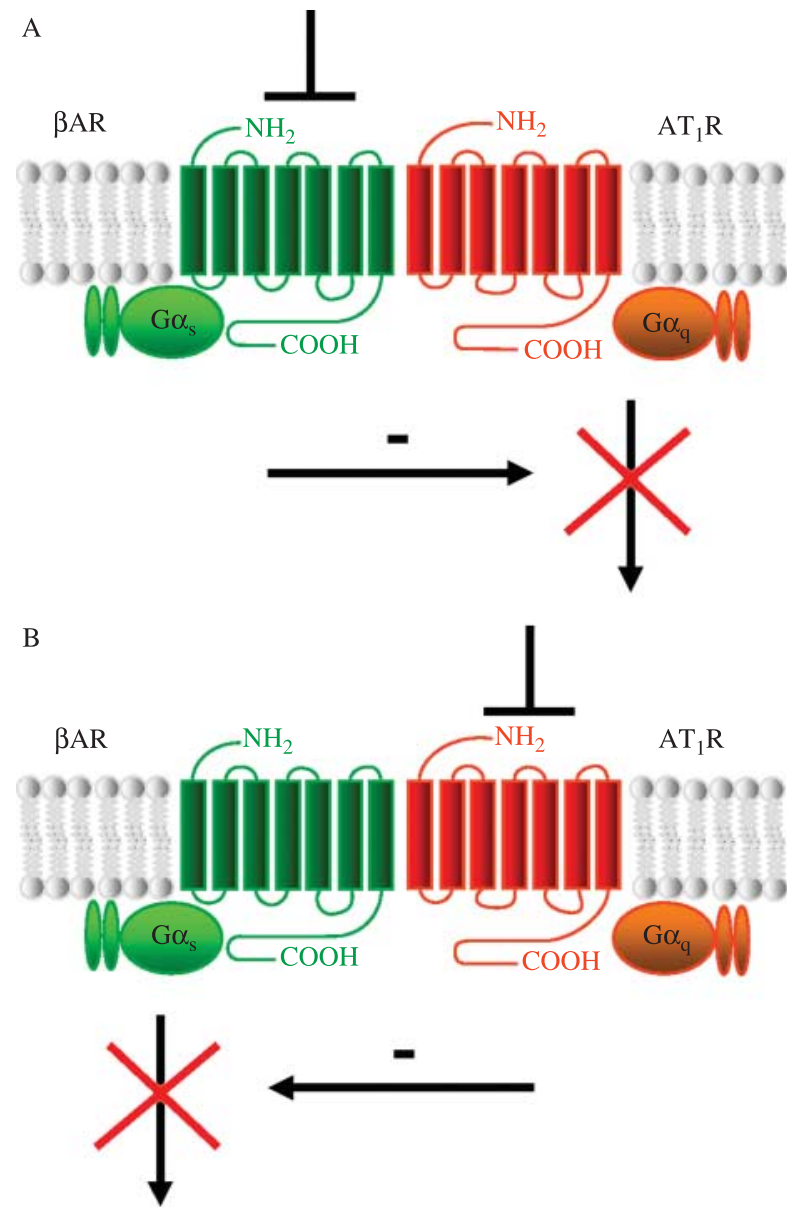

Figure 4 A cross-inhibition of $\beta$-adrenergic $(\beta A R)$ and $A_{1} T_{1}$ receptors $\left(A T_{1} R\right.$; Barki-Harrrington et al. 2003). (A) Pharmacological inhibition of the $\beta A R$ can inhibit the signaling of the heterodimerized $A T_{1} R$ and $(B)$ the inhibition of the $A T_{1} R$ can inhibit the signaling of the activated $\beta A R$.

2003). Interestingly, whereas $\beta$-adrenergic receptors are sensitive to valsartan, an $\mathrm{AT}_{1}$ receptor blocker, in the heart, they are unaffected by this drug in endothelial cells, which express a far greater ratio of $\beta$-adrenergic receptor to $\mathrm{AT}_{1}$ receptors (Barki-Harrington et al. 2003). Using mutant receptors that were insensitive to the $\mathrm{AT}_{1}$ receptor blocker, candesartan (Szidonya et al. 2007), or a G-protein couplingdeficient receptor (Gaborik et al. 2003, Wei et al. 2003), it was also demonstrated that cross-inhibition of $\mathrm{AT}_{1}$ receptor homo-oligomers can also occur (Karip et al. 2007). The inhibitory effect observed in these studies may reflect the notion that the optimal binding of a G-protein requires two interacting GPCRs (Filipek et al. 2004), but it is also possible that the conformational change induced by the binding of the inverse agonists used in these studies causes allosteric inhibition of the associated receptor. In fact, a cross-inhibition of the above-mentioned mutant $\mathrm{AT}_{1}$ receptors (Karip et al. 2007) suggest that an activated $A_{1}$ receptor associated with a 
G-protein coupling-deficient receptor can stimulate inositol phosphate signaling.

These and other functional data clearly indicate that a functionally important molecular interaction between GPCRs does occur. However, it will probably remain a matter of debate for more time, whether these interactions have a well-defined structural base, such as formation of receptor oligomers, or these interactions are indirect, and involve other proteins (or lipids). Despite this controversy, in our opinion receptor oligomerization is a useful paradigm to explain pharmacological properties of receptors that require direct or indirect interactions between GPCR molecules. Understanding of the functionally important interactions between GPCRs and their role in tissuespecific pharmacological actions of GPCR ligands is an important task. Recently, IUPHAR has worked out the criteria to define functionally relevant hetero-oligomeric interactions between GPCRs (Pin et al. 2007). According to these recommendations in order to define heterooligomeric interactions between GPCRs at least two of the following three conditions should be met. They are: 1) evidence for physical association in native tissue or primary cells (based on immunological colocalization or co-immunoprecipitation), 2) identification of a specific functional property for the hetero-oligomeric receptors in native tissue and 3) the use of knockout animals or RNAi technology to provide information on the existence of hetero-oligomeric GPCRs in vivo (Pin et al. 2007). The consistent application of these criteria will help to clarify the physiological and pharmacological relevance of the interactions between GPCRs.

\section{Concluding remarks}

In summary, evidence obtained with a wide range of different methods is accumulating, which suggest that GPCRs function as dimers or oligomers. Although individual evidences can be, and most of them were, challenged based on methodical grounds, the multitude of available positive data suggest that some kind of dimerization, oligomerization, or clustering of most GPCRs does occur. However, it is apparently very difficult to obtain decisive evidence, whether these receptors are organized into well-defined structures, such as dimers or oligomers, and interact directly; or function in larger molecular complexes, where propagation of the information occurs via complex molecular networks. It is likely that this issue will not be fully resolved until the necessary tools are developed to obtain high-resolution snapshots of GPCRs in their native environment. Although it may take a lot more time for structural biologists to achieve this goal, dimerization, or oligomerization of GPCRs is a very useful paradigm for pharmacologists to study properties of receptors, which require functionally important clustering, such as allosteric modulation of ligand binding, co-internalization, altered signaling properties, or cross-inhibition. An elucidation of these interactions is an important immediate task since these are critical to understand the pharmacological effects of drugs targeted to receptors and to elucidate the physiological mechanism of action of hormones and other mediators that target GPCRs.

\section{Acknowledgements}

The work of the authors is supported by grants from the Hungarian Science Foundation (OTKA T-046445), the Ányos Jedlik program by the Agency for Research Fund Management and Research Exploitation, Hungary (NKFP1010/2005), and the Hungarian Ministry of Public Health (ETT 447/2006). We are grateful to Dr Gábor Turu for his helpful discussions of the manuscript. The authors declare that there is no conflict of interest that would prejudice the impartiality of the present work.

\section{References}

Agnati LF, Fuxe K, Zoli M, Rondanini C \& Ogren SO 1982 New vistas on synaptic plasticity: the receptor mosaic hypothesis of the engram. Medical Biology 60 183-190.

Agrawal L, Lu X, Qingwen J, VanHorn-Ali Z, Nicolescu IV, McDermott DH, Murphy PM \& Alkhatib G 2004 Role for CCR5Delta32 protein in resistance to $\mathrm{R} 5, \mathrm{R} 5 \mathrm{X} 4$, and $\mathrm{X} 4$ human immunodeficiency virus type 1 in primary CD4 + cells. Journal of Virology 78 2277-2287.

Angers S, Salahpour A, Joly E, Hilairet S, Chelsky D, Dennis M \& Bouvier M 2000 Detection of beta 2 -adrenergic receptor dimerization in living cells using bioluminescence resonance energy transfer (BRET). PNAS 97 3684-3689.

Arai R, Nakagawa H, Tsumoto K, Mahoney W, Kumagai I, Ueda H \& Nagamune T 2001 Demonstration of a homogeneous noncompetitive immunoassay based on bioluminescence resonance energy transfer. Analytical Biochemistry 289 77-81.

El Asmar L, Springael JY, Ballet S, Andrieu EU, Vassart G \& Parmentier M 2005 Evidence for negative binding cooperativity within CCR5-CCR2b heterodimers. Molecular Pharmacology 67 460-469.

Ayoub MA, Couturier C, Lucas-Meunier E, Angers S, Fossier P, Bouvier M \& Jockers R 2002 Monitoring of ligand-independent dimerization and ligand-induced conformational changes of melatonin receptors in living cells by bioluminescence resonance energy transfer. Journal of Biological Chemistry 277 21522-21528.

Ayoub MA, Levoye A, Delagrange P \& Jockers R 2004 Preferential formation of MT1/MT2 melatonin receptor heterodimers with distinct ligand interaction properties compared with MT2 homodimers. Molecular Pharmacology 66 312-321.

Bakker RA, Dees G, Carrillo JJ, Booth RG, Lopez-Gimenez JF, Milligan G, Strange PG \& Leurs R 2004 Domain swapping in the human histamine H1 receptor. Journal of Pharmacology and Experimental Therapeutics 311 131-138.

Baneres JL \& Parello J 2003 Structure-based analysis of GPCR function: evidence for a novel pentameric assembly between the dimeric leukotriene B4 receptor BLT1 and the G-protein. Journal of Molecular Biology 329 815-829.

Barki-Harrington L, Luttrell LM \& Rockman HA 2003 Dual inhibition of beta-adrenergic and angiotensin II receptors by a single antagonist: a functional role for receptor-receptor interaction in vivo. Circulation 108 1611-1618.

Baxter JD \& Funder JW 1979 Hormone receptors. New England Journal of Medicine 301 1149-1161. 
Bayburt TH, Leitz AJ, Xie G, Oprian DD \& Sligar SG 2007 Transducin activation by nanoscale lipid bilayers containing one and two rhodopsins. Journal of Biological Chemistry 282 14875-14881.

Benkirane M, Jin DY, Chun RF, Koup RA \& Jeang KT 1997 Mechanism of transdominant inhibition of CCR 5-mediated HIV-1 infection by ccr5delta32. Journal of Biological Chemistry 272 30603-30606.

Bockaert J \& Pin JP 1999 Molecular tinkering of G protein-coupled receptors: an evolutionary success. EMBO Journal 18 1723-1729.

Bockaert J, Roussignol G, Becamel C, Gavarini S, Joubert L, Dumuis A, Fagni L \& Marin P 2004 GPCR-interacting proteins (GIPs): nature and functions. Biochemical Society Transactions 32 851-855.

Boute N, Jockers R \& Issad T 2002 The use of resonance energy transfer in high-throughput screening: BRET versus FRET. Trends in Pharmacological Sciences 23 351-354.

Bouvier M 2001 Oligomerization of G-protein-coupled transmitter receptors. Nature Reviews. Neuroscience 2 274-286.

Bouvier M, Heveker N, Jockers R, Marullo S \& Milligan G 2007 BRET analysis of GPCR oligomerization: newer does not mean better. Nature Methods 4 3-4.

Breitwieser GE $2004 \mathrm{G}$ protein-coupled receptor oligomerization: implications for $G$ protein activation and cell signaling. Circulation Research 94 17-27.

Bulenger S, Marullo S \& Bouvier M 2005 Emerging role of homo- and heterodimerization in G-protein-coupled receptor biosynthesis and maturation. Trends in Pharmacological Sciences 26 131-137.

Calebiro D, de Filippis T, Lucchi S, Covino C, Panigone S, Beck-Peccoz P, Dunlap D \& Persani L 2005 Intracellular entrapment of wild-type TSH receptor by oligomerization with mutants linked to dominant TSH resistance. Human Molecular Genetics 14 2991-3002.

Canals M, Marcellino D, Fanelli F, Ciruela F, de Benedetti P, Goldberg SR, Neve K, Fuxe K, Agnati LF, Woods AS et al. 2003 Adenosine A2Adopamine D2 receptor-receptor heteromerization: qualitative and quantitative assessment by fluorescence and bioluminescence energy transfer. Journal of Biological Chemistry 278 46741-46749.

Catt KJ \& Dufau ML 1977 Peptide hormone receptors. Annual Review of Physiology 39 529-557.

Chabre M \& le Maire M 2005 Monomeric G-protein-coupled receptor as a functional unit. Biochemistry 44 9395-9403.

Chabre M, Cone R \& Saibil H 2003 Biophysics: is rhodopsin dimeric in native retinal rods? Nature $\mathbf{4 2 6} 30-31$.

Cherezov V, Rosenbaum DM, Hanson MA, Rasmussen SG, Thian FS, Kobilka TS, Choi HJ, Kuhn P, Weis WI, Kobilka BK et al. 2007 Highresolution crystal structure of an engineered human beta2-adrenergic $\mathrm{G}$ protein-coupled receptor. Science 318 1258-1265.

Chudakov DM, Lukyanov S \& Lukyanov KA 2005 Fluorescent proteins as a toolkit for in vivo imaging. Trends in Biotechnology 23 605-613.

Clark AJL, Baig AH, Noon L, Swords FM, Hunyady L \& King PJ 2003 Expression, desensitization, and internalization of the ACTH receptor (MC2R). Annals of the New York Academy of Sciences 994 111-117.

Conn PM, Rogers DC, Stewart JM, Niedel J \& Sheffield T 1982 Conversion of a gonadotropin-releasing hormone antagonist to an agonist. Nature $\mathbf{2 9 6}$ 653-655.

Cornea A, Janovick JA, Maya-Nunez G \& Conn PM 2001 Gonadotropinreleasing hormone receptor microaggregation. Rate monitored by fluorescence resonance energy transfer. Journal of Biological Chemistry 276 2153-2158.

Coulon V, Audet M, Homburger V, Bockaert J, Fagni L, Bouvier M \& Perroy J 2008 Subcellular imaging of dynamic protein interactions by bioluminescence resonance energy transfer. Biophysical Journal 94 1001-1009.

Couve A, Filippov AK, Connolly CN, Bettler B, Brown DA \& Moss SJ 1998 Intracellular retention of recombinant $\mathrm{GABAB}$ receptors. Journal of Biological Chemistry 273 26361-26367.

Cvejic S \& Devi LA 1997 Dimerization of the delta opioid receptor: implication for a role in receptor internalization. Journal of Biological Chemistry 272 26959-26964.

Damak S, Rong M, Yasumatsu K, Kokrashvili Z, Varadarajan V, Zou S, Jiang P, Ninomiya Y \& Margolskee RF 2003 Detection of sweet and umami taste in the absence of taste receptor T1r3. Science 301 850-853.
Davis ME, Akera T, Brody TM \& Watson L 1977 Opiate receptor: cooperativity of binding observed in brain slices. PNAS 74 5764-5766.

Dell'Orco D, Seeber M \& Fanelli F 2007 Monomeric dark rhodopsin holds the molecular determinants for transducin recognition: insights from computational analysis. FEBS Letters 581 944-948.

Dinger MC, Bader JE, Kobor AD, Kretzschmar AK \& Beck-Sickinger AG 2003 Homodimerization of neuropeptide y receptors investigated by fluorescence resonance energy transfer in living cells. Journal of Biological Chemistry 278 10562-10571.

Ernst OP, Gramse V, Kolbe M, Hofmann KP \& Heck M 2007 Monomeric G protein-coupled receptor rhodopsin in solution activates its $G$ protein transducin at the diffusion limit. PNAS 104 10859-10864.

Filipek S, Krzysko KA, Fotiadis D, Liang Y, Saperstein DA, Engel A \& Palczewski K 2004 A concept for $G$ protein activation by $G$ proteincoupled receptor dimers: the transducin/rhodopsin interface. Photochemical \& Photobiological Sciences 3 628-638.

Floyd DH, Geva A, Bruinsma SP, Overton MC, Blumer KJ \& Baranski TJ 2003 C5a receptor oligomerization. II. Fluorescence resonance energy transfer studies of a human $G$ protein-coupled receptor expressed in yeast. Journal of Biological Chemistry 278 35354-35361.

Foord SM, Bonner TI, Neubig RR, Rosser EM, Pin JP, Davenport AP, Spedding M \& Harmar AJ 2005 International Union of Pharmacology. XLVI. G protein-coupled receptor list. Pharmacological Reviews 57 279-288.

Förster T 1948 Zwischenmolekulare Energiewanderung und Fluoreszenz. Annales de Physique 2 55-75.

Fotiadis D, Liang Y, Filipek S, Saperstein DA, Engel A \& Palczewski K 2003a Atomic-force microscopy: rhodopsin dimers in native disc membranes. Nature 421 127-128.

Fotiadis D, Liang Y, Filipek S, Saperstein DA, Engel A \& Palczewski K 2003b Biophysics (communication arising): is rhodopsin dimeric in native retinal rods? Nature 42631.

Fotiadis D, Jastrzebska B, Philippsen A, Muller DJ, Palczewski K \& Engel A 2006 Structure of the rhodopsin dimer: a working model for G-proteincoupled receptors. Current Opinion in Structural Biology 16 252-259.

Fredholm BB, Hokfelt T \& Milligan G 2007 G-protein-coupled receptors: an update. Acta Physiologica 190 3-7.

Fredriksson R \& Schioth HB 2005 The repertoire of G-protein-coupled receptors in fully sequenced genomes. Molecular Pharmacology 67 1414-1425.

Fredriksson R, Lagerstrom MC, Lundin LG \& Schioth HB 2003 The G-protein-coupled receptors in the human genome form five main families. Phylogenetic analysis, paralogon groups, and fingerprints. Molecular Pharmacology 63 1256-1272.

Gáborik Z, Jagadeesh G, Zhang M, Spät A, Catt KJ \& Hunyady L 2003 The role of a conserved region of the second intracellular loop in AT1 angiotensin receptor activation and signaling. Endocrinology 144 2220-2228.

Galperin E, Verkhusha VV \& Sorkin A 2004 Three-chromophore FRET microscopy to analyze multiprotein interactions in living cells. Nature Methods 1 209-217.

Galvez T, Duthey B, KniazeffJ, Blahos J, Rovelli G, Bettler B, Prezeau L \& Pin JP 2001 Allosteric interactions between GB1 and GB2 subunits are required for optimal GABA(B) receptor function. EMBO Journal 20 2152-2159.

Gassmann M, Shaban H, Vigot R, Sansig G, Haller C, Barbieri S, Humeau Y, Schuler V, Muller M, Kinzel B et al. 2004 Redistribution of GABAB(1) protein and atypical $\mathrm{GABAB}$ responses in $\mathrm{GABAB}(2)$-deficient mice. Journal of Neuroscience 24 6086-6097.

Giepmans BN, Adams SR, Ellisman MH \& Tsien RY 2006 The fluorescent toolbox for assessing protein location and function. Science 312 217-224.

Gines S, Hillion J, Torvinen M, Le Crom S, Casado V, Canela EI, Rondin S, Lew JY, Watson S, Zoli M et al. 2000 Dopamine D1 and adenosine A1 receptors form functionally interacting heteromeric complexes. PNAS 97 8606-8611.

Gouldson PR, Higgs C, Smith RE, Dean MK, Gkoutos GV \& Reynolds CA 2000 Dimerization and domain swapping in G-protein-coupled receptors: a computational study. Neuropsychopharmacology 23 S60-S77.

Gregan B, Jurgensen J, Papsdorf G, Furkert J, Schaefer M, Beyermann M, Rosenthal W \& Oksche A 2004 Ligand-dependent differences in the internalization of endothelin A and endothelin B receptor heterodimers. Journal of Biological Chemistry 279 27679-27687. 
Gripentrog JM, Kantele KP, Jesaitis AJ \& Miettinen HM 2003 Experimental evidence for lack of homodimerization of the $\mathrm{G}$ protein-coupled human $\mathrm{N}$-formyl peptide receptor. Journal of Immunology 171 3187-3193.

Hague C, Uberti MA, Chen Z, Bush CF, Jones SV, Ressler KJ, Hall RA \& Minneman KP 2004a Olfactory receptor surface expression is driven by association with the beta2-adrenergic receptor. PNAS 101 13672-13676.

Hague C, Uberti MA, Chen Z, Hall RA \& Minneman KP $2004 b$ Cell surface expression of alpha1D-adrenergic receptors is controlled by heterodimerization with alpha1B-adrenergic receptors. Journal of Biological Chemistry 279 15541-15549.

Hague C, Lee SE, Chen Z, Prinster SC, Hall RA \& Minneman KP 2006 Heterodimers of alpha1B- and alpha1D-adrenergic receptors form a single functional entity. Molecular Pharmacology 69 45-55.

Hanson SM, Gurevich EV, Vishnivetskiy SA, Ahmed MR, Song X \& Gurevich VV 2007 Each rhodopsin molecule binds its own arrestin. PNAS 104 3125-3128.

Hastings JW 1996 Chemistries and colors of bioluminescent reactions: a review. Gene 173 5-11.

Hebert TE, Moffett S, Morello JP, Loisel TP, Bichet DG, Barret C \& Bouvier M 1996 A peptide derived from a beta2-adrenergic receptor transmembrane domain inhibits both receptor dimerization and activation. Journal of Biological Chemistry 271 16384-16392.

Heroux M, Hogue M, Lemieux S \& Bouvier M 2007 Functional calcitonin gene-related peptide receptors are formed by the asymmetric assembly of a calcitonin receptor-like receptor homo-oligomer and a monomer of receptor activity-modifying protein-1. Journal of Biological Chemistry 282 31610-31620.

Herrick-Davis K, Grinde E \& Mazurkiewicz JE 2004 Biochemical and biophysical characterization of serotonin 5-HT2C receptor homodimers on the plasma membrane of living cells. Biochemistry 43 13963-13971.

Hu CD \& Kerppola TK 2003 Simultaneous visualization of multiple protein interactions in living cells using multicolor fluorescence complementation analysis. Nature Biotechnology 21 539-545.

Hu CD, Chinenov Y \& Kerppola TK 2002 Visualization of interactions among bZIP and Rel family proteins in living cells using bimolecular fluorescence complementation. Molecular Cell 9 789-798.

Hunyady L \& Catt KJ 2006 Pleiotropic AT1 receptor signaling pathways mediating physiological and pathogenic actions of angiotensin II. Molecular Endocrinology 20 953-970.

Jacoby E, Bouhelal R, Gerspacher M \& Seuwen K 2006 The 7 TM G-protein-coupled receptor target family. ChemMedChem 1 761-782.

James JR, Oliveira MI, Carmo AM, Iaboni A \& Davis SJ 2006 A rigorous experimental framework for detecting protein oligomerization using bioluminescence resonance energy transfer. Nature Methods 3 1001-1006.

Jastrzebska B, Fotiadis D, Jang GF, Stenkamp RE, Engel A \& Palczewski K 2006 Functional and structural characterization of rhodopsin oligomers. Journal of Biological Chemistry 281 11917-11922.

Jones KA, Borowsky B, Tamm JA, Craig DA, Durkin MM, Dai M, Yao WJ, Johnson M, Gunwaldsen C, Huang LY et al. 1998 GABA(B), receptors function as a heteromeric assembly of the subunits $\mathrm{GABA}(\mathrm{B}) \mathrm{R} 1$ and GABA(B)R2. Nature 396 674-679.

Jordan BA \& Devi LA 1999 G-protein-coupled receptor heterodimerization modulates receptor function. Nature 399 697-700.

Karip E, Turu G, Süpeki K, Szidonya L \& Hunyady L 2007 Cross-inhibition of angiotensin AT(1) receptors supports the concept of receptor oligomerization. Neurochemistry International 51 261-267.

Karpa KD, Lin R, Kabbani N \& Levenson R 2000 The dopamine D3 receptor interacts with itself and the truncated D3 splice variant d3nf: D3-D3nf interaction causes mislocalization of D3 receptors. Molecular Pharmacology $\mathbf{5 8}$ 677-683.

Katragadda M, Maciejewski MW \& Yeagle PL 2004 Structural studies of the putative helix 8 in the human beta(2) adrenergic receptor: an NMR study. Biochimica et Biophysica Acta 1663 74-81.

Kaupmann K, Malitschek B, Schuler V, Heid J, Froestl W, Beck P, Mosbacher J, Bischoff S, Kulik A, Shigemoto R et al. 1998 GABA(B)-receptor subtypes assemble into functional heteromeric complexes. Nature 396 683-687.
Kerppola TK 2006 Design and implementation of bimolecular fluorescence complementation (BiFC) assays for the visualization of protein interactions in living cells. Nature Protocols 1 1278-1286.

Kirber MT, Chen K \& Keaney JF, Jr 2007 YFP photoconversion revisited: confirmation of the CFP-like species. Nature Methods 4 767-768.

Kroeger KM, Pfleger KD \& Eidne KA 2003 G-protein coupled receptor oligomerization in neuroendocrine pathways. Frontiers in Neuroendocrinology 24 254-278.

Latif R, Graves P \& Davies TF 2001 Oligomerization of the human thyrotropin receptor: fluorescent protein-tagged hTSHR reveals posttranslational complexes. Journal of Biological Chemistry 276 45217-45224.

Lee SP, O’Dowd BF, Ng GY, Varghese G, Akil H, Mansour A, Nguyen T \& George SR 2000 Inhibition of cell surface expression by mutant receptors demonstrates that D2 dopamine receptors exist as oligomers in the cell. Molecular Pharmacology 58 120-128.

Levoye A, Dam J, Ayoub MA, Guillaume JL, Couturier C, Delagrange P \& Jockers R 2006 The orphan GPR50 receptor specifically inhibits MT1 melatonin receptor function through heterodimerization. EMBO Journal 25 3012-3023.

Li J, Edwards PC, Burghammer M, Villa C \& Schertler GF 2004 Structure of bovine rhodopsin in a trigonal crystal form. Journal of Molecular Biology 343 1409-1438.

Liang Y, Fotiadis D, Filipek S, Saperstein DA, Palczewski K \& Engel A 2003 Organization of the $G$ protein-coupled receptors rhodopsin and opsin in native membranes. Journal of Biological Chemistry 278 21655-21662.

Liang Y, Fotiadis D, Maeda T, Maeda A, Modzelewska A, Filipek S, Saperstein DA, Engel A \& Palczewski K 2004 Rhodopsin signaling and organization in heterozygote rhodopsin knockout mice. Journal of Biological Chemistry 279 48189-48196.

Limbird LE \& Lefkowitz RJ 1976 Negative cooperativity among betaadrenergic receptors in frog erythrocyte membranes. Journal of Biological Chemistry 251 5007-5014.

Lodowski DT, Salom D, Le T I, Teller DC, Ballesteros JA, Palczewski K \& Stenkamp RE 2007 Crystal packing analysis of Rhodopsin crystals. Journal of Structural Biology 158 455-462.

Lopez-Gimenez JF, Canals M, Pediani JD \& Milligan G 2007 The alpha1badrenoceptor exists as a higher-order oligomer: effective oligomerization is required for receptor maturation, surface delivery, and function. Molecular Pharmacology 71 1015-1029.

Luttrell LM 2006 Transmembrane signaling by G protein-coupled receptors. Methods in Molecular Biology 332 3-49.

Maggio R, Vogel Z \& Wess J 1993a Coexpression studies with mutant muscarinic/adrenergic receptors provide evidence for intermolecular 'cross-talk' between G-protein-linked receptors. PNAS 90 3103-3107.

Maggio R, Vogel Z \& Wess J $1993 b$ Reconstitution of functional muscarinic receptors by co-expression of amino- and carboxyl-terminal receptor fragments. FEBS Letters 319 195-200.

Mansoor SE, Palczewski K \& Farrens DL 2006 Rhodopsin self-associates in asolectin liposomes. PNAS 103 3060-3065.

Marullo S \& Bouvier M 2007 Resonance energy transfer approaches in molecular pharmacology and beyond. Trends in Pharmacological Sciences $\mathbf{2 8}$ 362-365.

Maurel D, Kniazeff J, Mathis G, Trinquet E, Pin JP \& Ansanay H 2004 Cell surface detection of membrane protein interaction with homogeneous time-resolved fluorescence resonance energy transfer technology. Analytical Biochemistry 329 253-262.

McVey M, Ramsay D, Kellett E, Rees S, Wilson S, Pope AJ \& Milligan G 2001 Monitoring receptor oligomerization using time-resolved fluorescence resonance energy transfer and bioluminescence resonance energy transfer. The human delta -opioid receptor displays constitutive oligomerization at the cell surface, which is not regulated by receptor occupancy. Journal of Biological Chemistry 276 14092-14099.

Mercier JF, Salahpour A, Angers S, Breit A \& Bouvier M 2002 Quantitative assessment of beta 1 - and beta 2 -adrenergic receptor homo- and heterodimerization by bioluminescence resonance energy transfer. Journal of Biological Chemistry 277 44925-44931. 
Mesnier D \& Baneres JL 2004 Cooperative conformational changes in a G-protein-coupled receptor dimer, the leukotriene B(4) receptor BLT1. Journal of Biological Chemistry 279 49664-49670.

Meyer BH, Segura JM, Martinez KL, Hovius R, George N, Johnsson K \& Vogel H 2006 FRET imaging reveals that functional neurokinin-1 receptors are monomeric and reside in membrane microdomains of live cells. PNAS 103 2138-2143.

Milligan G 2006 G-protein-coupled receptor heterodimers: pharmacology, function and relevance to drug discovery. Drug Discovery Today 11 541-549.

Milligan G \& Bouvier M 2005 Methods to monitor the quaternary structure of G protein-coupled receptors. FEBS Journal 272 2914-2925.

Milligan G, Ramsay D, Pascal G \& Carrillo JJ 2003 GPCR dimerisation. Life Sciences 74 181-188.

Minneman KP 2007 Heterodimerization and surface localization of G protein coupled receptors. Biochemical Pharmacology 73 1043-1050.

Monnot C, Bihoreau C, Conchon S, Curnow KM, Corvol P \& Clauser E 1996 Polar residues in the transmembrane domains of the type 1 angiotensin II receptor are required for binding and coupling. Reconstitution of the binding site by co-expression of two deficient mutants. Journal of Biological Chemistry 271 1507-1513.

Mukherjee C, Caron MG, Coverstone M \& Lefkowitz RJ 1975 Identification of adenylate cyclase-coupled beta-adrenergic receptors in frog erythrocytes with (minus)-[3-H] alprenolol. Journal of Biological Chemistry 250 4869-4876.

Nag K, Sultana N, Kato A \& Hirose S 2007 Headless splice variant acting as dominant negative calcitonin receptor. Biochemical and Biophysical Research Communications 362 1037-1043.

Nelson G, Hoon MA, Chandrashekar J, Zhang Y, Ryba NJ \& Zuker CS 2001 Mammalian sweet taste receptors. Cell 106 381-390.

Nelson G, Chandrashekar J, Hoon MA, Feng L, Zhao G, Ryba NJ \& Zuker CS 2002 An amino-acid taste receptor. Nature 416 199-202.

Noon LA, Franklin JM, King PJ, Goulding NJ, Hunyady L \& Clark AJL 2002 Failed export of the adrenocorticotrophin receptor from the endoplasmic reticulum in non-adrenal cells: evidence in support of a requirement for a specific adrenal accessory factor. Journal of Endocrinology 174 17-25.

Overton MC \& Blumer KJ 2000 G-protein-coupled receptors function as oligomers in vivo. Current Biology 10 341-344.

Palczewski K, Kumasaka T, Hori T, Behnke CA, Motoshima H, Fox BA, Le TI, Teller DC, Okada T, Stenkamp RE et al. 2000 Crystal structure of rhodopsin: a G protein-coupled receptor. Science 289 739-745.

Parameswaran N \& Spielman WS 2006 RAMPs: the past, present and future. Trends in Biochemical Sciences 31 631-638.

Park PS \& Wells JW 2004 Oligomeric potential of the M2 muscarinic cholinergic receptor. Journal of Neurochemistry 90 537-548.

Patel RC, Kumar U, Lamb DC, Eid JS, Rocheville M, Grant M, Rani A, Hazlett T, Patel SC, Gratton E et al. 2002a Ligand binding to somatostatin receptors induces receptor-specific oligomer formation in live cells. PNAS 99 3294-3299.

Patel RC, Lange DC \& Patel YC 2002b Photobleaching fluorescence resonance energy transfer reveals ligand-induced oligomer formation of human somatostatin receptor subtypes. Methods 27 340-348.

Perroy J, Pontier S, Charest PG, Aubry M \& Bouvier M 2004 Real-time monitoring of ubiquitination in living cells by BRET. Nature Methods 1 203-208.

Pfleger KD \& Eidne KA 2003 New technologies: bioluminescence resonance energy transfer (BRET) for the detection of real time interactions involving G-protein coupled receptors. Pituitary 6 141-151.

Pfleger KD \& Eidne KA 2005 Monitoring the formation of dynamic G-protein-coupled receptor-protein complexes in living cells. Biochemical Journal 385 625-637.

Pfleger KD, Dromey JR, Dalrymple MB, Lim EM, Thomas WG \& Eidne KA 2006 Extended bioluminescence resonance energy transfer (eBRET) for monitoring prolonged protein-protein interactions in live cells. Cellular Signalling 18 1664-1670.

Pin JP, Neubig R, Bouvier M, Devi L, Filizola M, Javitch JA, Lohse MJ, Milligan G, Palczewski K, Parmentier M et al. 2007 International Union of
Basic and Clinical Pharmacology. LXVII. Recommendations for the recognition and nomenclature of $\mathrm{G}$ protein-coupled receptor heteromultimers. Pharmacological Reviews 59 5-13.

Prinster SC, Hague C \& Hall RA 2005 Heterodimerization of g proteincoupled receptors: specificity and functional significance. Pharmacological Reviews $\mathbf{5 7}$ 289-298.

Pritchard LM, Logue AD, Taylor BC, Ahlbrand R, Welge JA, Tang Y, Sharp FR \& Richtand NM 2006 Relative expression of D3 dopamine receptor and alternative splice variant D3nf mRNA in high and low responders to novelty. Brain Research Bulletin 70 296-303.

Ramsay D, Kellett E, McVey M, Rees S \& Milligan G 2002 Homo- and hetero-oligomeric interactions between G-protein-coupled receptors in living cells monitored by two variants of bioluminescence resonance energy transfer (BRET): hetero-oligomers between receptor subtypes form more efficiently than between less closely related sequences. Biochemical Journal 365 429-440.

Rasmussen SG, Choi HJ, Rosenbaum DM, Kobilka TS, Thian FS, Edwards PC, Burghammer M, Ratnala VR, Sanishvili R, Fischetti RF et al. 2007 Crystal structure of the human beta2 adrenergic G-protein-coupled receptor. Nature $450383-387$.

van Rheenen J, Langeslag M \& Jalink K 2004 Correcting confocal acquisition to optimize imaging of fluorescence resonance energy transfer by sensitized emission. Biophysical Journal 86 2517-2529.

Rocheville M, Lange DC, Kumar U, Sasi R, Patel RC \& Patel YC 2000 Subtypes of the somatostatin receptor assemble as functional homo- and heterodimers. Journal of Biological Chemistry 275 7862-7869.

Roess DA, Horvat RD, Munnelly H \& Barisas BG 2000 Luteinizing hormone receptors are self-associated in the plasma membrane. Endocrinology 141 4518-4523.

Salahpour A \& Masri B 2007 Experimental challenge to a 'rigorous' BRET analysis of GPCR oligomerization. Nature Methods 4 599-600.

Salim K, Fenton T, Bacha J, Urien-Rodriguez H, Bonnert T, Skynner HA, Watts E, Kerby J, Heald A, Beer M et al. 2002 Oligomerization of G-protein-coupled receptors shown by selective co-immunoprecipitation. Journal of Biological Chemistry 277 15482-15485.

Salom D, Lodowski DT, Stenkamp RE, Le TI, Golczak M, Jastrzebska B, Harris T, Ballesteros JA \& Palczewski K 2006 Crystal structure of a photoactivated deprotonated intermediate of rhodopsin. PNAS $\mathbf{1 0 3}$ 16123-16128.

Schertler GF 2005 Structure of rhodopsin and the metarhodopsin I photointermediate. Current Opinion in Structural Biology 15 408-415.

Schoneberg T, Liu J \& Wess J 1995 Plasma membrane localization and functional rescue of truncated forms of a $\mathrm{G}$ protein-coupled receptor. Journal of Biological Chemistry 270 18000-18006.

Schulz A, Grosse R, Schultz G, Gudermann T \& Schoneberg T 2000 Structural implication for receptor oligomerization from functional reconstitution studies of mutant V2 vasopressin receptors. Journal of Biological Chemistry 275 2381-2389.

Smith RD, Baukal AJ, Zolyomi A, Gaborik Z, Hunyady L, Sun L, Zhang M, Chen HC \& Catt KJ 1998 Agonist-induced phosphorylation of the endogenous AT1 angiotensin receptor in bovine adrenal glomerulosa cells. Molecular Endocrinology 12 634-644.

Springael JY, Le Minh PN, Urizar E, Costagliola S, Vassart G \& Parmentier M 2006 Allosteric modulation of binding properties between units of chemokine receptor homo- and hetero-oligomers. Molecular Pharmacology 69 1652-1661.

Springael JY, Urizar E, Costagliola S, Vassart G \& Parmentier M 2007 Allosteric properties of $\mathrm{G}$ protein-coupled receptor oligomers. Pharmacology and Therapeutics 115 410-418.

Sraer J, Baud L, Cosyns JP, Verroust P, Nivez MP \& Ardaillou R 1977 High affinity binding of 125I-angiotensin II to rat glomerular basement membranes. Journal of Clinical Investigation 59 69-81.

Stanasila L, Perez JB, Vogel H \& Cotecchia S 2003 Oligomerization of the alpha $1 \mathrm{a}$ - and alpha $1 \mathrm{~b}$-adrenergic receptor subtypes. Potential implications in receptor internalization. Journal of Biological Chemistry 278 40239-40251. 
Storez H, Scott MG, Issafras H, Burtey A, Benmerah A, Muntaner O, Piolot T, Tramier M, Coppey-Moisan M, Bouvier M et al. 2005 Homo- and heterooligomerization of beta-arrestins in living cells. Journal of Biological Chemistry $28040210-40215$

Szidonya L, Süpeki K, Karip E, Turu G, Várnai P, Clark AJL \& Hunyady L 2007 AT(1) receptor blocker-insensitive mutant AT(1A) angiotensin receptors reveal the presence of $\mathrm{G}$ protein-independent signaling in $\mathrm{C} 9$ cells. Biochemical Pharmacology 73 1582-1592.

Tao YX 2006 Inactivating mutations of $\mathrm{G}$ protein-coupled receptors and diseases: structure-function insights and therapeutic implications. Pharmacology and Therapeutics 111 949-973.

Tate RL, Schwartz HI, Holmes JM \& Kohn LD 1975 Thyrotropin receptors in thyroid plasma membranes. Characteristics of thyrotropin binding and solubilization of thyrotropin receptor activity by tryptic digestion. Journal of Biological Chemistry 250 6509-6515.

Terrillon S \& Bouvier M 2004 Roles of G-protein-coupled receptor dimerization. EMBO Reports 5 30-34.

Terrillon S, Durroux T, Mouillac B, Breit A, Ayoub MA, Taulan M, Jockers R, Barberis C \& Bouvier M 2003 Oxytocin and vasopressin V1a and V2 receptors form constitutive homo- and heterodimers during biosynthesis. Molecular Endocrinology 17 677-691.

Thaler C, Vogel SS, Ikeda SR \& Chen H 2006 Photobleaching of YFP does not produce a CFP-like species that affects FRET measurements. Nature Methods 3 491-493.

Thomas WG 1999 Regulation of angiotensin II type 1 (AT1) receptor function. Regulatory Peptides 79 9-23.

Tyndall JD \& Sandilya R 2005 GPCR agonists and antagonists in the clinic. Medicinal Chemistry 1 405-421.

Urizar E, Montanelli L, Loy T, Bonomi M, Swillens S, Gales C, Bouvier M, Smits G, Vassart G \& Costagliola S 2005 Glycoprotein hormone receptors: link between receptor homodimerization and negative cooperativity. EMBO Journal 24 1954-1964.

Valentin G, Verheggen C, Piolot T, Neel H, Coppey-Moisan M \& Bertrand E 2005 Photoconversion of YFP into a CFP-like species during acceptor photobleaching FRET experiments. Nature Methods 2801.

Veatch W \& Stryer L 1977 The dimeric nature of the gramicidin A transmembrane channel: conductance and fluorescence energy transfer studies of hybrid channels. Journal of Molecular Biology 113 89-102.
Venkatesan S, Petrovic A, Van Ryk DI, Locati M, Weissman D \& Murphy PM 2002 Reduced cell surface expression of CCR 5 in CCR5Delta 32 heterozygotes is mediated by gene dosage, rather than by receptor sequestration. Journal of Biological Chemistry 277 2287-2301.

Wallrabe H \& Periasamy A 2005 Imaging protein molecules using FRET and FLIM microscopy. Current Opinion in Biotechnology 16 19-27.

Wei H, Ahn S, Shenoy SK, Karnik SS, Hunyady L, Luttrell LM \& Lefkowitz RJ 2003 Independent beta-arrestin 2 and G protein-mediated pathways for angiotensin II activation of extracellular signal-regulated kinases 1 and 2 . PNAS 100 10782-10787.

White JH, Wise A, Main MJ, Green A, Fraser NJ, Disney GH, Barnes AA, Emson P, Foord SM \& Marshall FH 1998 Heterodimerization is required for the formation of a functional $\mathrm{GABA}(\mathrm{B})$ receptor. Nature 396 679-682.

Whorton MR, Bokoch MP, Rasmussen SG, Huang B, Zare RN, Kobilka B \& Sunahara RK 2007 A monomeric G protein-coupled receptor isolated in a high-density lipoprotein particle efficiently activates its G protein. PNAS 104 7682-7687.

Xu Y, Piston DW \& Johnson CH 1999 A bioluminescence resonance energy transfer (BRET) system: application to interacting circadian clock proteins. PNAS 96 151-156.

Xu H, Staszewski L, Tang H, Adler E, Zoller M \& Li X 2004 Different functional roles of T1R subunits in the heteromeric taste receptors. PNAS 101 14258-14263.

Zhao GQ, Zhang Y, Hoon MA, Chandrashekar J, Erlenbach I, Ryba NJ \& Zuker CS 2003 The receptors for mammalian sweet and umami taste. Cell 115 255-266.

Zhu X \& Wess J 1998 Truncated V2 vasopressin receptors as negative regulators of wild-type V2 receptor function. Biochemistry 37 15773-15784.

Received in final form 29 December 2007

Accepted 3 January 2008

Made available online as an Accepted Preprint 3 January 2008 